\title{
Acute stress in adulthood impoverishes social choices and triggers aggressiveness in preclinical models
}

\section{Anne Nosjean ${ }^{1}{ }^{*}$, Arnaud Cressant ${ }^{1}$, Fabrice de Chaumont ${ }^{2}$, Jean-Christophe Olivo-Marin ${ }^{2}$, Frédéric Chauveau ${ }^{3}$ and Sylvie Granon ${ }^{1}$}

${ }^{1}$ Centre de Neuroscience Paris Sud, Université Paris Sud 11 and Centre National de la Recherche Scientifique UMR 8195, Orsay, France

${ }^{2}$ Unité d'Analyse d'Images Quantitative, Institut Pasteur, Centre National de la Recherche Scientifique URA 2582, Paris, France

${ }^{3}$ Institut de Recherche Biomédicale des Armées, NCO, Unité NPS, Brétigny-sur-Orge, France

Edited by:

Benno Roozendaal, Radboud University Nijmegen Medical Centre, Netherlands

Reviewed by:

Antonio Armario, Universitat Autònoma de Barcelona, Spain Walter Adriani, Istituto Superiore di Sanità, Italy

*Correspondence:

Anne Nosjean, Centre de Neuroscience Paris Sud, Université Paris Sud 11 and Centre National de la Recherche Scientifique UMR 8195, Bâtiment 446, 15 Bd Clémenceau 91405 Orsay, France e-mail:anne.nosjean@u-psud.fr
Adult C57BL/6J mice are known to exhibit high level of social flexibility while mice lacking the $\beta 2$ subunit of nicotinic receptors $\left(\beta 2^{-/-}\right.$mice) present social rigidity. We asked ourselves what would be the consequences of a restraint acute stress ( $45 \mathrm{~min}$ ) on social interactions in adult mice of both genotypes, hence the contribution of neuronal nicotinic receptors in this process. We therefore dissected social interaction complexity of stressed and not stressed dyads of mice in a social interaction task. We also measured plasma corticosterone levels in our experimental conditions. We showed that a single stress exposure occurring in adulthood reduced and disorganized social interaction complexity in both C57BL/6J and $\beta 2^{-/-}$mice. These stress-induced maladaptive social interactions involved alteration of distinct social categories and strategies in both genotypes, suggesting a dissociable impact of stress depending on the functioning of the cholinergic nicotinic system. In both genotypes, social behaviors under stress were coupled to aggressive reactions with no plasma corticosterone changes. Thus, aggressiveness appeared a general response independent of nicotinic function. We demonstrate here that a single stress exposure occurring in adulthood is sufficient to impoverish social interactions: stress impaired social flexibility in C57BL/6J mice whereas it reinforced $\beta 2^{-/-}$mice behavioral rigidity.

Keywords: social interactions, decision, aggression, dominance, $\beta 2$ nicotinic receptor, corticosterone

\section{INTRODUCTION}

Social interactions involve highly integrative and adapted behaviors to make coherent decisions in specific environmental contexts. Social interactions are altered in numerous psychiatric pathologies, such as anxiety (Lukkes et al., 2009; Morrison and Heimberg, 2013), depression (Anisman and Matheson, 2005), schizophrenia (Marwick and Hall, 2008; Ritsner et al., 2013), drug abuse (Buckner et al., 2013), autism (Grzadzinski et al., 2013; Zafeiriou et al., 2013), post-traumatic stress disorders (Javidi and Yadollahie, 2012; Zoladz and Diamond, 2013), and under stressful conditions (Lupien et al., 2009; Del Giudice et al., 2011; Javidi and Yadollahie, 2012; Starcke and Brand, 2012). Social interactions require sequential, and sometimes competing, choices that integrate both physiological and psychological parameters that are peculiar to the individual. Among these parameters, those that affect emotional, motivational, and memory processes are crucial (Adolphs, 2010; Gasbarri and Tomaz, 2012; Adolphs and Anderson, 2013).

The prevalence of stress-induced pathologies has increased tremendously in industrialized countries, to the extent that they have become a major global health problem. An individual's ability to prevent, correct, or escape stressful situations to reach a state of personal well-being reflects the overall health of society. Numerous studies have addressed the short- and long-term effects of chronic stress on brain physiology and plasticity, on cognitive function in adults, and on cognitive function during childhood and adolescence (Veenema, 2009; Marquez et al., 2013); other studies have focused on the social impact of chronic stress and the triggering of aggressiveness (Sandi et al., 2008; McEwen, 2012; Barik et al., 2013). Aggressive behavior is common and adaptive between rodents of the same species and, like all mammals, they cope with social threats by making physiological and behavioral adjustments that can increase their ability to escape or fight. The stress-response system and the activation of the hypothalamus-pituitary-adrenal axis (HPA) axis are known to support these adjustments (for reviews, Koolhaas et al., 1999; Nevo, 2007). In laboratory, acute stress has also been intensely studied, particularly its impact on memory (for reviews, Roozendaal, 2002, 2003; McEwen, 2006, 2007; Sandi and Pinelo-Nava, 2007; Roozendaal et al., 2009; Van Der Kooij and Sandi, 2012). It has also been shown to affect decision-making in humans (Porcelli and Delgado, 2009; Starcke and Brand, 2012; Pabst et al., 2013a,b) and in rodents (Quartermain et al., 1996; Toledo-Rodriguez and Sandi, 2011; Shafiei et al., 2012; Butts et al., 2013). Surprisingly, however, the consequences of acute stress on the complexity of social interactions have received little attention to date, despite the fact that, in people's minds, it is widely believed that acute stress can produce disproportionate 
and potentially disastrous reactions in social circumstances (but see a recent study in humans by Von Dawans et al., 2012). It is known that stress alters the function of the prefrontal cortex (PFC), a brain structure implicated in the social cognition and not fully developed before adulthood (Marquez et al., 2013). However, the effect of acute stress in adults, i.e., when the brain is fully developed, on social interaction has never been clearly established. We thus intended to address this question here.

Mice that lacked the $\beta 2$ subunit of nicotinic receptors $\left(\beta 2^{-/-}\right.$ mice) did not exhibit cognitive defects (Zoli et al., 1999; Wiklund et al., 2009) and showed normal levels of motivation in response to natural rewards (Chabout et al., 2013); however, they presented less flexible behaviors i.e., exhibited behavioral rigidity when motivations were in conflicting (Granon et al., 2003; de Chaumont et al., 2012). We recently evidenced that the role of neuronal nicotinic receptors -nAChRs- depends on the degree of safety or uncertainty of a behavioral context: in a secured social context, $\beta 2$-nAChRs are not necessary for integrating social information or social rewards, whereas in uncertain context they are essential for the management and the hierarchical organization of choices (Avale et al., 2011; Serreau et al., 2011; Chabout et al., 2013). Functional nAChRs and efficient cholinergic neurotransmission are thus needed for adapted social skills and other executive functions (Granon et al., 2003; Kobayashi et al., 2013) as well as for the control of emotions and mood either in animals (Anderson and Brunzell, 2012; Mineur et al., 2013) or in humans (Tsai et al., 2012). In addition, an interesting study evidenced the effect of prenatal stress on the upregulation of nAChRs at adulthood (Schultz et al., 2013). Together, the data suggest a direct role of nAChRs in social skills as well as in stress management but the contribution of the various nicotinic receptors subunits, in particular that of the $\beta 2$ subunit in these processes, is not defined. We expected here to provide novel information to this regard.

Social behaviors are complex behaviors that require sequential choices to achieve an action and integrate both emotional and motivational processes (Adolphs, 2010; Starcke and Brand, 2012). In our laboratory, we currently used a social interaction task in which a previously isolated adult mouse, e.g., deprived of social contact for 3-4 weeks, makes continuous free choices between exploration of a novel environment and social contacts with an unknown social-housed mouse of same sex and age (Granon et al., 2003; Avale et al., 2011; Serreau et al., 2011; de Chaumont et al., 2012). Such isolation time was chosen in order to reinforce the rewarding value of social contacts (Granon et al., 2003; Krach et al., 2010) since non-isolated animals were not highly interested in social interaction (Avale et al., 2011; Chabout et al., 2013). Similar isolation procedures during adulthood, largely used in many learning paradigms, seem to be unsufficient alone to induce chronic stress (Sakakibara et al., 2012). Furthermore, in our social interaction task, the isolated animals explored the novel environment before the task. If not, the amount of time spent in social contact dropped around 15 percent (Avale et al., 2011). Under these experimental conditions, C57BL/6J mice, which are known to be highly sociable (Sankoorikal et al., 2006), made frequent social contacts; exhibited high levels of exploration (Avale et al., 2011), a normal level of dominant behaviors, and no aggressive behaviors (Coura et al., 2013). In contrast, adult $\beta 2^{-/-}$mice favored social contacts to the detriment of the exploration and lacked behavioral flexibility and adaptation of ongoing behavior to environmental changes (for review, Kehagia et al., 2010). They also showed more dominant behaviors than C57BL/6J mice (Coura et al., 2013). Since we established that $\beta 2^{-/-}$mice lacked behavioral flexibility and exhibit more rigid choices in social or in non-social choice tasks, we hypothesized that they would be more sensitive to stress and as such, we wondered whether stress could worsen or prevent $\beta 2^{-/-}$mice social rigidity.

In a recent work, we validated a software highlighting social behaviors (MiceProfiler, de Chaumont et al., 2012). In particular we investigated in detail the difference between the analyses conducted by two independent investigators from that using the software. We showed that some events were similarly scored by manual and automatic analyses (e.g., contacts) while some were under evaluated by manual scoring (follows) or simply undetectable by visual analysis (complex events). In the aforementioned study, we only focused on some remarkable social events occurring during the task. Here, we further investigated each behavioral event of each mice of the dyad, i.e., contact and single events, postures, dynamic and stop events, to figure out their origins, their consequences and their relationships, and to provide a full comprehensive analysis of the natural behavior of $\mathrm{C} 57 \mathrm{BL} / 6 \mathrm{~J}$ and $\beta 2^{-/-}$mice. We also investigated the immediate consequences of an acute restraint stress $(45 \mathrm{~min}$ ) applied to the isolated mouse of the dyad on social interactions in C57BL/6J mice and in $\beta 2^{-/-}$mice, to assess the contribution of $\beta 2^{-/-}$ neuronal nicotinic receptors in this process. We focused on adult animals since $\beta 2^{-/-}$mice social defects were previously identified in adults (Granon et al., 2003; de Chaumont et al., 2012). As acute stress in adult humans was reported to enhance habit behavior to the detriment of flexible behavior (Starcke and Brand, 2012), we expected here to find reduced social flexibility and more stereotyped actions in both genotypes.

\section{MATERIALS AND METHODS ANIMALS}

Male C57BL/6J mice and $\beta 2^{-/-}$knockout mice purchased from Charles Rivers Laboratories (L'Arbresle Cedex, France) were used in the present study. $\beta 2^{-/-}$mice were generated from a $129 / \mathrm{Sv}$ Embryonic Stem cell line as previously described (Picciotto et al., 1995) and backcrossed onto the C57BL/6J strain for 20 generations. As they were shown to be at more than $99.99 \%$ C57BL/6J by a genomic analysis using 400 markers, C57BL/6J mice were used as control of $\beta 2^{-/-}$animals.

All experimental procedures were carried out in accordance with the European Communities Council Directive of 24 November 1986 (86/609/EEC), EU Directive 2010/63/EU, Decree N 2013-118 of February 1st, 2013, and the French National Committee (87/848). Experiments were conducted in order to reduce the number of mice used and their level of discomfort. C57BL/6J and $\beta 2^{-/-}$mice, $10-11$ weeks old, were group-housed (four mice/cage; size of the cages L: $26.5 \mathrm{~cm}, \mathrm{l}: 16.5 \mathrm{~cm}, \mathrm{H}$ : $13.5 \mathrm{~cm}$ ) at their arrival to acclimatize to the animal facilities (food and water ad libitum, room temperature $20-22^{\circ} \mathrm{C}$ ) under a 12/12 h light/dark cycle (light on at $7.30 \mathrm{am}$ ). 


\section{BEHAVIORAL APPARATUS FOR SOCIAL INTERACTION TEST}

The social interaction task was performed in a transparent Plexiglass box (L: $50 \mathrm{~cm} \times 1: 25 \mathrm{~cm} \times \mathrm{H}: 31 \mathrm{~cm}$ ) located in an experimental room with light level set at 100-110 Lux by indirect white bulbs. For each experiment, the floor of the cage was covered with clean sawdust. The box was placed under a camera connected to a computer located outside of the experimental room.

\section{BEHAVIORAL PROTOCOLS AND MEASURES}

Social behaviors were studied in dyads of male mice composed by an Isolated Host mouse (IH) and a Social Visitor mouse (SV) brought together for the first time. IH mice were individually housed 4 weeks before the social interaction task, while SV mice remained group-housed. IH mice (either C57BL/6J or $\beta 2^{-/-}$ mice) were submitted or not to an acute stress. SV mice were always not stressed C57BL/6J male mice. The choice of 4 weeks social isolation was made after pilot experiments. All behavioral experiments were performed from 9.00 a.m. to 2.00 p.m. (i.e., in the lit phase of the dark/light cycle). Each isolated animal randomly assigned to the stressed groups was placed for $45 \mathrm{~min}$ in a Falcon ${ }^{\circledR}$ tube. After $5 \mathrm{~min}$ in its home cage, $\mathrm{IH}$ mouse was placed in the experimental box for $30 \mathrm{~min}$ exploration. Then, a SV mouse was gently introduced in the box, in the corner opposite to the IH mouse. The delay from the beginning of the stress to the end of the social task (i.e., $84 \mathrm{~min}$ ) was compatible with expression of the c-fos protein in the PFC (Weinberg et al., 2007; Avale et al., 2011), an area previously shown to be critically involved in social interaction (Avale et al., 2011). Control mice were treated similarly, except that they were not submitted to stress (Supplementary Figure 1). In this study, 19 isolated C57BL/6J mice were used (11 were not stressed, i.e., C57BL/6J mice, 8 were subjected to the acute stress, i.e., C57BL/6J Stress mice) and 16 isolated $\beta 2^{-/-}$mice ( 9 were not stressed, i.e., $\beta 2^{-/-}$ mice and 7 were submitted to an acute stress, i.e., $\beta 2^{-/-}$Stress mice). In addition, 35 group-housed C57BL/6J animals served as SV mice.

Social interactions between SV and IH mice were videotaped and analyzed using Mice Profiler software (de Chaumont et al., 2012). Affiliative behaviors studied are explained in Supplementary Table 1. We distinguished contact events, relative positions between mice, dynamic complex events initiated by SV or IH mice, and stop events. Dynamic events were dissociated in first order events (escapes, approaches or follows), second order events (first-order event preceded or followed by a contact) and third order events (2 successions of 2 second-order events). The number and duration of behavioral events of each mouse of the dyad were quantified during the $4 \mathrm{~min}$ of the social interaction task.

Chronograms and density graphs were built to illustrate the evolution of the quantitative data in the course of mice dyad interactions. They show behavioral variation of a specific event within an animal and between animals over time. As such, they allow to perceive the stability or instability of given behaviors. For each mouse or each dyad, chronograms depict the frame-by-frame occurrence and duration of a particular event, and thus provide an immediate visualization of its frequency. Density graphs (built from chronograms) represent the temporal evolution of the density of a given event, i.e., the sum of the time in which an event is happening vs. the total time of the bin (grouped here in bins of $30 \mathrm{~s}$ ). As such, they represent the same information as chronograms but averaged for all mice of a specific group. We also built transitional graphs to illustrate the probability of incidence of one event or posture on the next or the previous one in a sequence.

Finally, we scored dominance and aggressiveness by off line manual analysis. Dominance index was defined as the number of "paw control" (i.e., the number of times IH mouse placed its forepaw on the head or on the back of the SV mouse). Aggressiveness was indexed by the cumulated number of tail rattling and attacks over the 4 min of the experiment. Latencies to first attack and first tail rattling were also scored.

\section{PLASMA CORTICOSTERONE ASSAYS}

Biochemical measures of plasma corticosterone were carried out in a pseudo random order by an experimenter blind to mice genotype and stress conditions. Experiments were performed in the same time scale than behavioral ones (10 a.m. -1.30 p.m., i.e., in the lit phase of the dark/light cycle), animals being treated similarly than for behavioral experiments (see Supplementary Figure 1). Trunk blood was collected after mice decapitation. Sacrifices were done $60 \mathrm{~min}$ after transfer of mice from animal facility, i.e., after habituation to the experimental room (condition $\mathrm{A}, n=4$ for both genotypes), just after the restraint stress (condition $\mathrm{B}, n=6$ for each genotype) and at the end of the exploration period, i.e., at the time at which social interaction should take place (condition C, $n=6$ not stressed and 7 stressed C57BL/6J mice, $n=7$ not stressed and 9 stressed $\beta 2^{-/-}$mice). Knowing that baseline levels were already measured $60 \mathrm{~min}$ after the exit of the animal facility (condition A), waiting $45 \mathrm{~min}$ more was extremely unlikely to increase plasma corticosterone levels by itself, so we didn't measure it in additional groups of not stressed animals (condition B). After centrifugation (5000 g $10 \mathrm{~min}$ at $4^{\circ} \mathrm{C}$ ), the supernatant was stored at $-20^{\circ} \mathrm{C}$. Corticosterone levels were quantified using an enzyme immunoassay commercial kit (DetectX ${ }^{\circledR}$, Arbor Assays). Samples were included into the linear part of the standard curve. Limit of detection was determined as $0.17 \mu \mathrm{g} / \mathrm{dl}$.

\section{STATISTICAL ANALYSIS}

Normal distribution (assessed by Shapiro-Wilkonson test) and equality of variance (evaluated by equal variance test) were first tested using Sigmaplot 12.0. When both were statistically significant, main factor effects and interactions were tested with TwoWay ANOVAs followed by Fisher LSD Method tests when appropriate. When normality and/or equal variance were not statistically significant, Kruskal-Wallis One-Way ANOVA then MannWhitney $U$-tests were performed when appropriate. Results were reported as means \pm SEM. $P$ values $\leq 0.05$ were considered statistically significant. Correlations between behavioral events were performed using Spearman test and a Bonferroni correction was applied for multiple comparisons. Statistically threshold was thus set at $p \leq 0.0022$. 


\section{RESULTS}

\section{BEHAVIORAL RESULTS}

\section{Contacts events during social interaction (Figure 1, Table 1)}

For similar number, $\beta 2^{-/-}$mice spent significantly more time in close contact a1 with their partner than C57BL/6J mice [genotype effect: $\left.F_{(1,31)}=5.81, p=0.022\right]$ with a stress* genotype interaction $\left[F_{(1,34)}=10.43, p=0.003\right]$. Acute stress only decreased a1 duration in $\beta 2^{-/-}$mice [stress effect: $F_{(1,31)}=12.77, p=0.001$; Fisher LSD Method: $p<0.001]$.

No statistical changes in number and duration for oral-oral contacts (a2 event) were detected ( $H=5.83, d f=3, p=0.12$, NS; $H=5.49, d f=3, p=0.14$, NS; respectively).

In regards $\mathrm{IH}$ oral-genital contacts with SV mouse (a3 event), $\beta 2^{-/-}$mice made significantly more such contacts than C57BL/6J
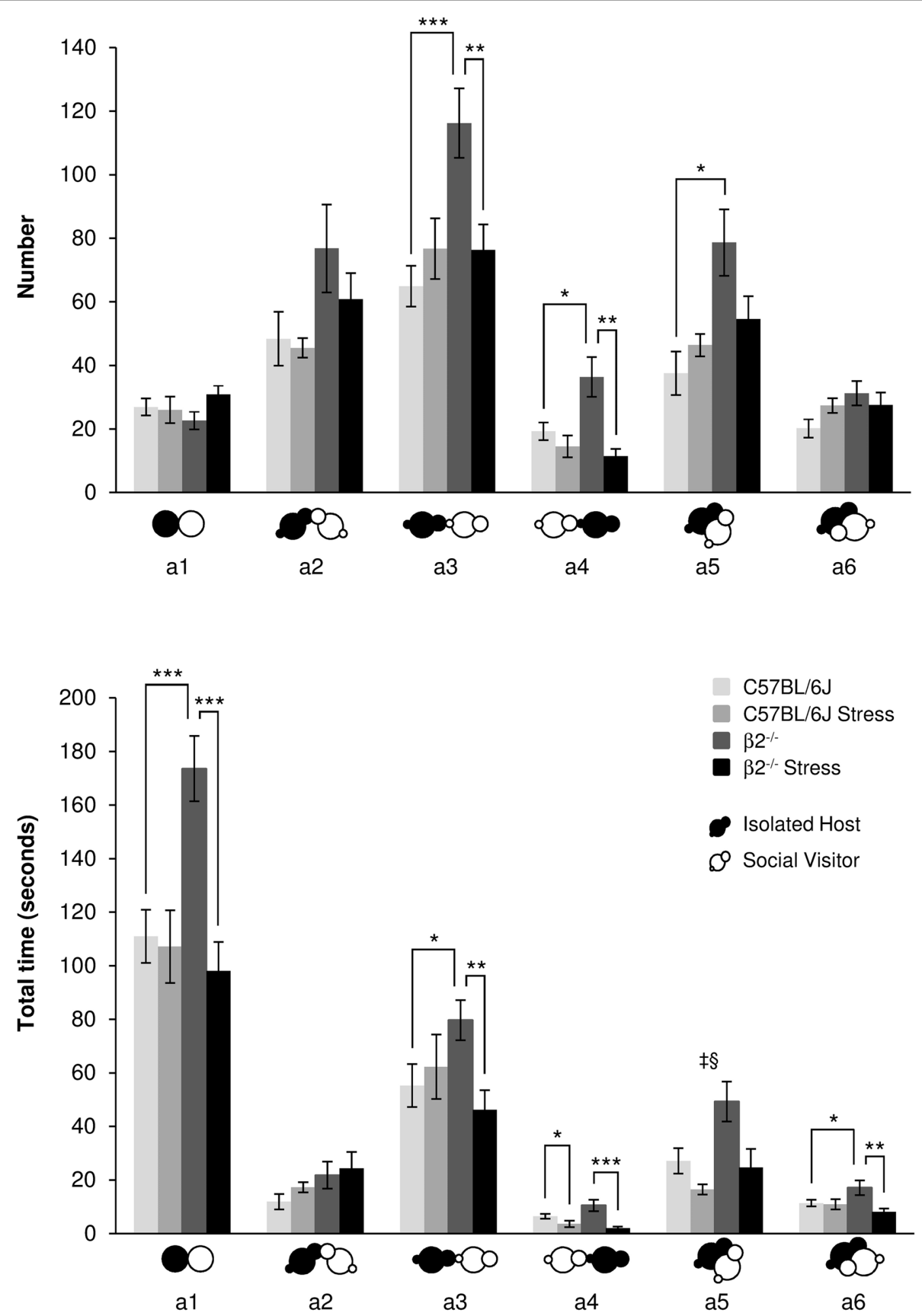

FIGURE 1 | Contact events during social interaction. The number (Top) and the total time (Bottom) of the different types of contact (a1 to a6 as referred in Table 1 and Supplementary Table 1) between IH and SV mice were quantified during the $4 \mathrm{~min}$ of the social interaction task. IH mice were submitted or not to an acute stress (C57BL/6J: $n=11 ; \beta 2^{-/-}: n=9$; C57BL/6J Stress: $n=8 ; \beta 2^{-/}$Stress: $\left.n=7\right)$. Data are expressed as means \pm SEM. ${ }^{*} p \leq 0.05,{ }^{* *} p \leq 0.01,{ }^{* * *} p \leq 0.001,{ }^{\ddagger}$ Genotype effect: $p \leq 0.009$, ${ }^{\S}$ Stress effect $p=0.003$. 
Table 1 | Data summary of social interaction task.

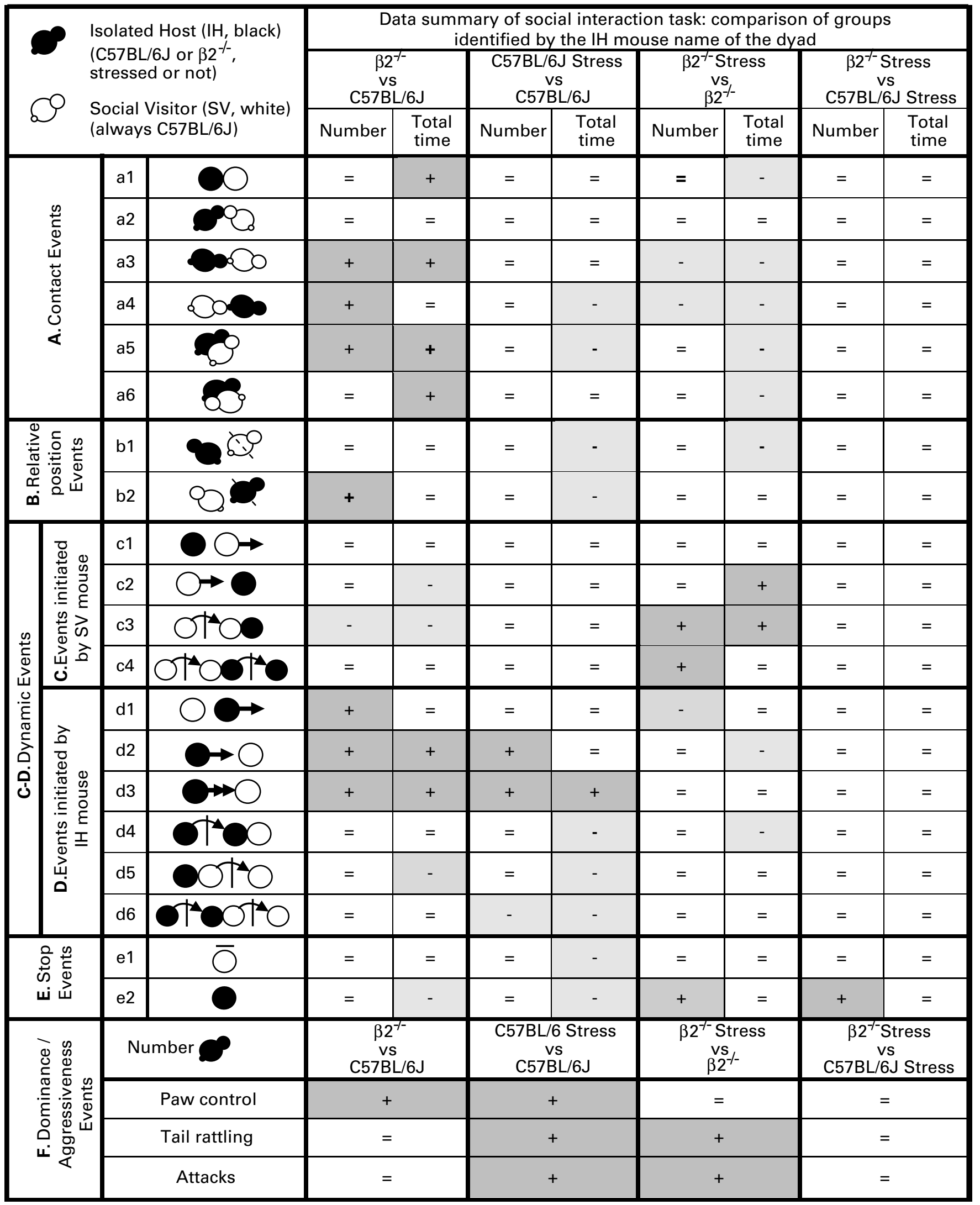




\section{Table 1 | Continued}

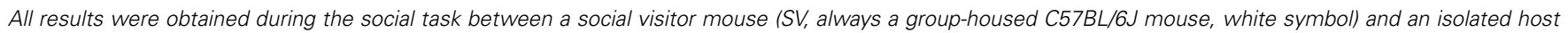

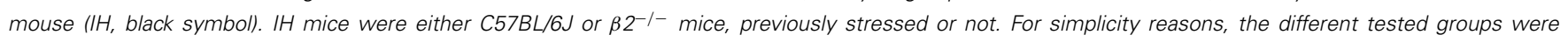

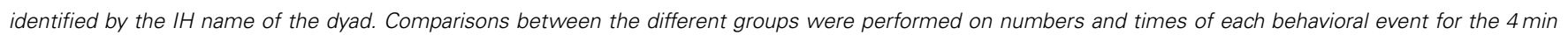

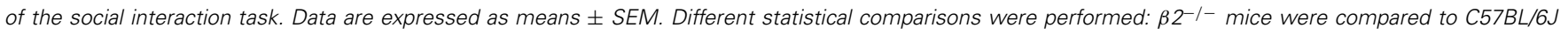

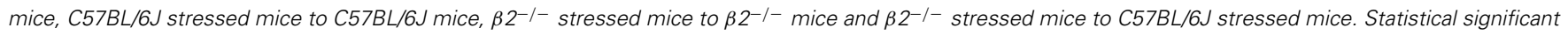

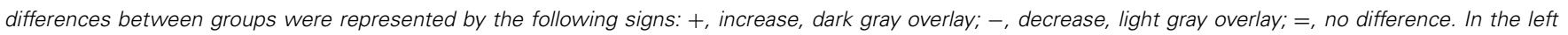

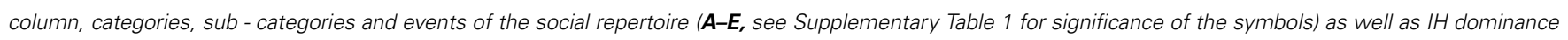

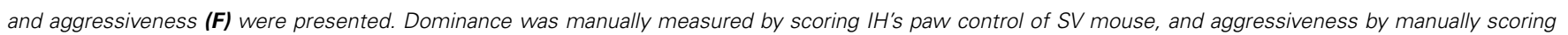
IH's tail rattling and attacks. C57BL/6J: $n=11 ; \beta 2^{-1-}: n=9 ; C 57 B L / 6 J$ Stress: $n=8 ; \beta 2^{-1-}$ Stress, $n=7$.

mice $\left[F_{(1,31)}=9.13, p=0.005\right]$ with a stress* genotype interactions $\left[F_{(1,34)}=9.47, p=0.004\right]$ and no stress effect $\left[F_{(1,34)}=\right.$ 2.79, $p=0.105$, NS]. Further Fisher LSD test revealed significant decreased number of a3 event in $\beta 2^{-/-}$mice after stress $(p<0.003)$. A stress* ${ }^{*}$ genotype interactions was also found for a3 duration $\left[F_{(1,34)}=5.66, p=0.024\right]$ : a3 event lasted longer in $\beta 2^{-/-}$mice compared to C57BL/6J mice (Fisher LSD Method $p<0.036$ ) and decreased in $\beta 2^{-/-}$mice after stress (Fisher LSD Method $p<0.012$ ).

SV mouse made more oral-genital contacts a4 with $\beta 2^{-/-}$ mice than with C57BL/6J mice $(H=13.45, d f=3, p=0.004$; Mann-Whitney, $p=0.024)$. Acute stress had no effect on this event in $\mathrm{C} 57 \mathrm{BL} / 6 \mathrm{~J}$ mice but decreased it in $\beta 2^{-/-}$animals $(H=13.45, d f=3, p=0.004$; Mann-Whitney, $p=0.003)$. Also, acute stress decreased a4 duration both in C57BL/6J $(H=17.12, d f=3, p<0.001$; Mann-Whitney, $p=0.043)$ and $\beta 2^{-/-}$mice $(H=17.12, d f=3, p<0.001$; Mann-Whitney, $p=0.001)$.

Concerning side-by-side contacts, a5 event increased in number $(H=10.80, d f=3, p=0.013$; Mann-Whitney, $p=0.015)$ in $\beta 2^{-/-}$mice compared to C57BL/6J animals. No other statistical changes were detected. Duration of this event also increased in $\beta 2^{-/-}$mice $\left[F_{(1,31)}=7.85, p=0.009\right]$ with no stress* genotype interaction $\left[F_{(1,34)}=1.68, p=0.21\right.$, NS $]$ but a stress effect in both genotypes $\left[F_{(1,31)}=10.61, p=0.003\right]$. Finally, no statistical changes were detected for a6 number. Analysis of a6 duration showed no genotype effect $\left[F_{(1,31)}=0.67, p=0.42\right.$, NS $]$ but a stress* genotype interaction $\left[F_{(1,34)}=5.53, p=0.025\right]$. Fisher LSD Method revealed an increase of a6 duration in $\beta 2^{-/-}$mice compared to $\mathrm{C} 57 \mathrm{BL} / 6 \mathrm{~J}$ mice $(p=0.022)$. A stress effect was also detected $\left[F_{(1,31)}=6.76, p=0.014\right]$ : a6 duration decreased after stress in $\beta 2^{-/-}$mice (Fisher LSD tests: $p=0.002)$.

Overall, events that were increased in $\beta 2^{-/-}$mice as compared to $\mathrm{C} 57 \mathrm{BL} / 6 \mathrm{~J}$ were reduced in $\beta 2^{-/-}$animals after stress and reached $\mathrm{C} 57 \mathrm{BL} / 6 \mathrm{~J}$ values.

All contact events occurred during the course of the task for all groups of mice (Supplementary Figure 2) but, as a5, they may be less observed at the beginning of the experiment than toward the end. Contact events (a3-a6) decreased from 2 to $2.30 \mathrm{~min}$ in C57BL/6J mice, but increased or remained stable in $\beta 2^{-/-}$mice suggesting that $\mathrm{C} 57 \mathrm{BL} / 6 \mathrm{~J}$ mice exhibited a progressive decrease of interest for social contacts, and $\beta 2^{-/-}$mice, a steady one. Also, $\beta 2^{-/-}$mice, which are affected by the stress, showed a steady interest to contact their partner.
Thus, most contact subtypes were more numerous and lasted longer in $\beta 2^{-/-}$mice than in C57BL/6J mice. Overall, exposure to restraint stress did not alter contact behaviors of C57BL/6 J mice but drastically reduced them in $\beta 2^{-/-}$mice. They acquired a C57BL/6J social like behavior despite different evolution with time.

\section{Relative position events during social interaction (Figure 2, Table 1)}

The event b1 (IH mice behind SV mice) occurred similarly in $\mathrm{C} 57 \mathrm{BL} / 6 \mathrm{~J}$ and $\beta 2^{-/-}$mice [no genotype effect: $F_{(1,31)}=$ $3.85, p=0.06$, NS] for similar time [no genotype effect: $\left.F_{(1,31)}=0.69, p=0.41, \mathrm{NS}\right]$. No stress* genotype interactions were detected neither for number $\left[F_{(1,34)}=1.32, p=0.26\right.$, NS $]$ or duration $\left[F_{(1,31)}=0.013, p=0.91, \mathrm{NS}\right]$ for this relative position event. Stress reduced the total time of b1 event in both genotypes [stress effect: $F_{(1,31)}=4.88, p=0.035$ ].

The events b2 (SV mice behind IH mice) occurred more frequently in $\beta 2^{-/-}$mice as compared to C57BL/6J mice [genotype effect: $F_{(1,31)}=5.94, p=0.021$ ] for similar time [no genotype effect: $\left.F_{(1,31)}=0.15, p=0.70, \mathrm{NS}\right]$. Stress*genotype interaction $\left[F_{(1,34)}=4.44, p=0.043\right]$ and stress effect $\left[F_{(1,31)}=\right.$ $4.44, p=0.043]$ were only detected for b2 duration. Fisher LSD tests showed that acute stress reduced the total time of this b2 event in C57BL/6J $(p=0.004)$ but not in $\beta 2^{-/-}$mice $(p=0.99$, NS).

In all groups, b1 event was similarly stable all along the experiment. In contrast, b2 event gradually increased over time in both $\mathrm{C} 57 \mathrm{BL} / 6 \mathrm{~J}$ and $\beta 2^{-/-}$mice and remained steadily low in stressed C57BL/6J mice. This suggested that C57BL/6J and $\beta 2^{-/-}$ mice, but not stressed C57BL/6J mice, became used to have their partner behind them.

Thus, all groups of IH mice similarly and continuously preferred to be behind SV mice overtime. Acute stress reduced the total time that mice spent in both positions only in C57BL/6J mice and seemed to prevent stressed C57BL/6J mice to accustom to have their partner behind them.

\section{Dynamic events during social interaction}

To target specific dynamic behaviors, we dissociated those initiated by SV mice (Table 1C; Supplementary Table 1C) from those initiated by IH mice (Table 1D; Supplementary Table 1D). We dissociated first order events (escapes, approaches, or follows) from second order events (first-order event preceded or followed by a contact) and third order events (2 successions of 2 second-order events). 


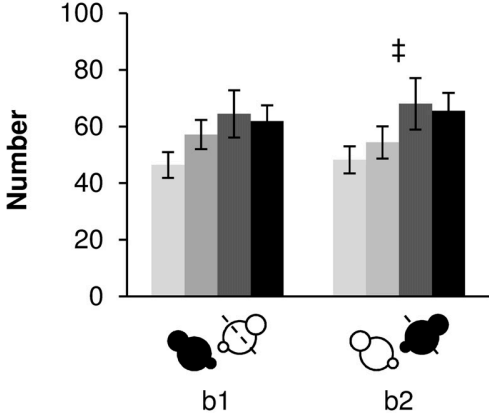

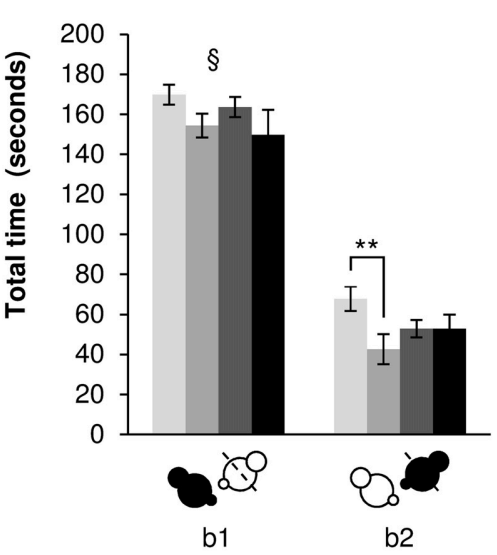

Chronograms and density graphs of $b 1$ and $b 2$ events
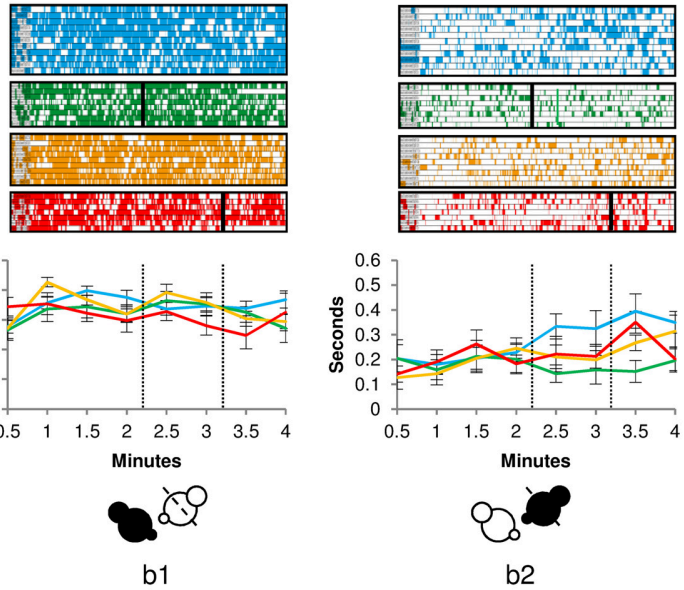

b1

b2

C57BL/6J C57BL/6J Stress $\quad \beta 2^{-/-} \quad \beta 2^{-/-S t r e s s}$

FIGURE 2 | Relative position events during social interaction. Histograms (Top) showed the number and the total time of the relative position events (b1 and b2 as referred in Table 1 and Supplementary Table 1) between $\mathrm{IH}$ and $\mathrm{SV}$, quantified during the $4 \mathrm{~min}$ of the social interaction task. IH mice were submitted or not to an acute stress. Data are expressed as means \pm SEM. ${ }^{* *} p \leq 0.01$, ${ }^{\ddagger}$ Genotype effect: $p=0.021,{ }^{\S}$ Stress effect $p=0.035$. Chronograms and density graphs (Bottom) illustrated the temporal evolution of the aforementioned b1 and b2 events throughout the $4 \mathrm{~min}$ of the experiment. In the chronograms, each line represents one dyad of IH - SV mice in a specific group. The length of each point is proportional to the duration of events. In the graphs,

(Continued)

\section{FIGURE 2 | Continued}

each line represented the mean of the temporal evolution of a given event for each group of mice. Vertical lines on chronograms and density graphs indicated the average latency to first attack in stressed C57BL/6J and stressed $\beta 2^{-/-}$mice (full and dotted lines). C57BL/6J: blue, $n=11$; C57BL/6J Stress: green, $n=8 ; \beta 2^{-/-}$: yellow, $n=9 ; \beta 2^{-/-}$Stress: red, $n=7$.

Events initiated by the visitor mouse (Figure 3, Table 1). For SV escapes number or duration (c1 event), there was no effect of genotype $\left[F_{(1,31)}=3.57, p=0.07\right.$, NS; $F_{(1,31)}=0.19, p=$ $0.665, \mathrm{NS}]$, no stress* genotype interaction $\left[F_{(1,34)}=3.19, p=\right.$ $\left.0.084, \mathrm{NS} ; F_{(1,34)}=0.11, p=0.74, \mathrm{NS}\right]$, nor effect of stress $\left[F_{(1,31)}=0.002, p=0.964, \mathrm{NS} ; F_{(1,31)}=3.30, p=0.079, \mathrm{NS}\right]$, respectively.

No statistical changes were detected for number of c2 event (IH mouse approached by SV mouse). SV mice approached more quickly a $\beta 2^{-/-}$than a C57BL/6J mouse $(H=14.56, d f=3, p=$ 0.002 ; Mann-Whitney, $p<0.001)$. This event lasted significantly longer in $\beta 2^{-/-}$mice after stress $(H=14.56, d f=3, p=0.002$; Mann-Whitney, $p=0.026)$.

SV approaches terminated by a social contact (c3 event) were significantly less numerous $(H=8.14, d f=3, p=0.043$; MannWhitney, $p=0.015)$ and shorter $(H=8.50, d f=3, p=0.037$; Mann-Whitney, $p=0.006)$ in presence of a $\beta 2^{-/-}$IH mouse than a C57BL/6J IH mouse. Acute stress significantly increased such SV action $(H=8.14, d f=3, p=0.043$; Mann-Whitney, $p=0.03)$ which lasted significantly longer $(H=8.50, d f=3$, $p=0.037$; Mann-Whitney, $p=0.034)$ only in presence of a $\beta 2^{-/-}$mice.

Finally, as regards c4 event, the only statistical change concerned its number that was significantly increased after stress in $\beta 2^{-/-}$mice compared to not stressed $\beta 2^{-/-}$mice $(H=11.15$, $d f=3, p=0.011$; Mann-Whitney, $p=0.004)$.

As a matter of fact, SV actions that were significantly reduced in presence of a $\beta 2^{-/-}$mice compared to C57BL/6J mice (c3, c4), increased after stress to reach $\mathrm{C} 57 \mathrm{BL} / 6 \mathrm{~J}$ mice values.

Approaches of SV mice (c2, Supplementary Figure 3) initially similarly highly represented in all groups, decreased quickly and drastically in not stressed animals, and more moderately but linearly in stressed ones to reach similar values at the end of the task. This suggested that SV mice expressed a strong interest for the different IH mice only at the beginning of the experiment and that their interest for their conspecific decreased overtime, whatever is the genotype and the emotional status of their social partner. The rare c4 events, (Supplementary Figure 3), very variable between and within dyads over time, may occur for long periods of time. Notably they may not be exhibited by all dyads, as illustrated by chronograms, and were particularly sporadic when SV faced a $\beta 2^{-/-}$mice.

Here, we showed that SV approaches, shorter in presence of a $\beta 2^{-/-}$mouse, were restored after stress. This revealed that the social approaches of SV mice were influenced by the $\beta 2^{-/-}$ genotype and their emotional status.

Events initiated by the Isolated Host mouse (Figure 4, Table 1). When IH mice were $\beta 2^{-/-}$animals, the number of first order 


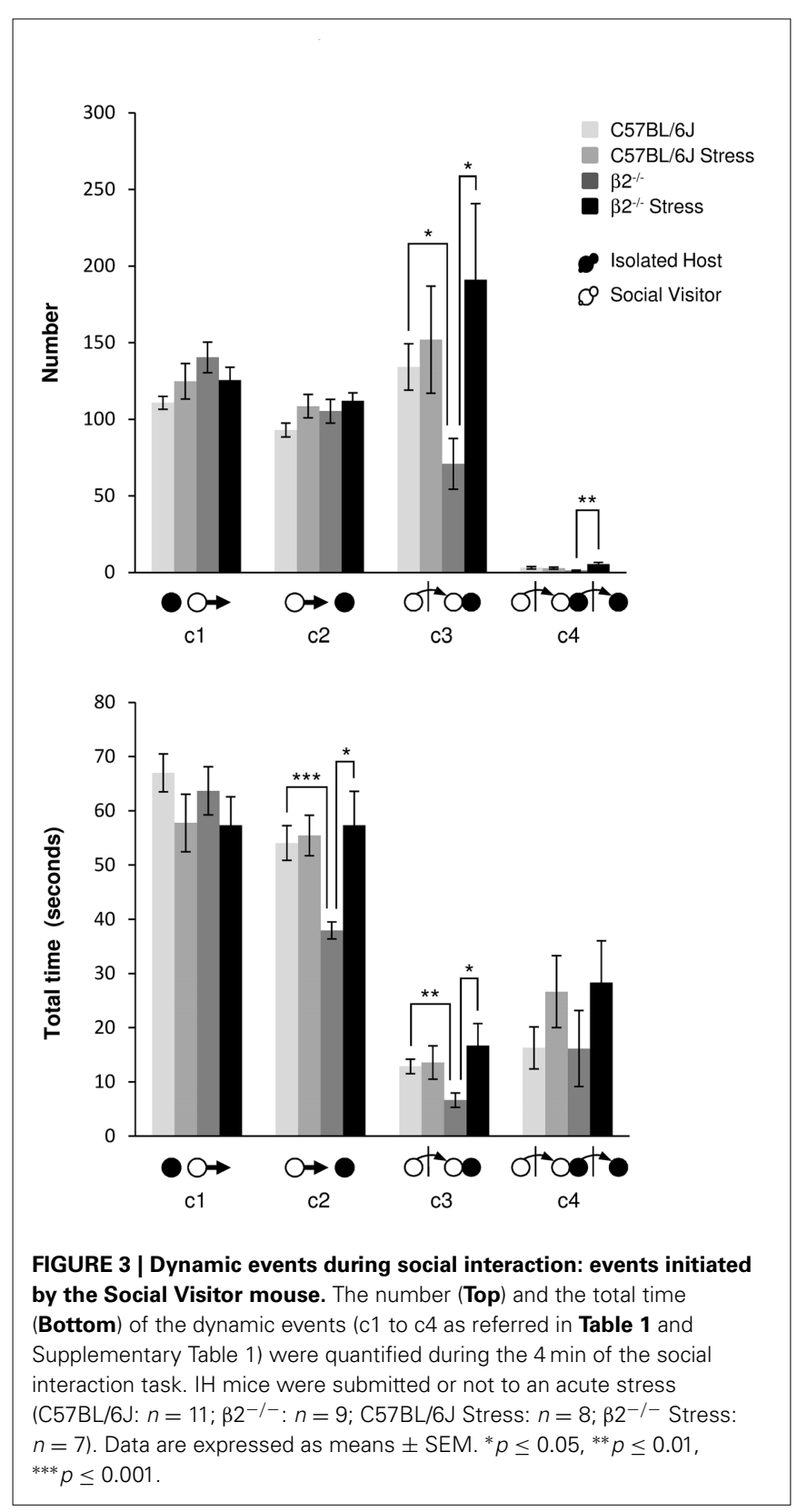

events significantly increased, e.g., escapes (d1: $H=9.99, d f=$ $3, p=0.019$; Mann-Whitney, $p=0.006)$, approaches $(\mathrm{d} 2: H=$ 16.49, $d f=3, p<0.001$; Mann-Whitney, $p=0.003$ ) and follow behaviors (d3: $H=12.65, d f=3, p=0.005$; Mann-Whitney, $p=0.009)$ as compared to $\mathrm{C} 57 \mathrm{BL} / 6 \mathrm{~J}$ mice. Stress* genotype interactions were detected for duration of both $\mathrm{d} 2$ and $\mathrm{d} 3$ events $\left[F_{(1,34)}=4.72, p=0.038\right.$ and $F_{(1,34)}=10.57, p=$ 0.003 , respectively]. Without stress, $\beta 2^{-/-}$mice spent more time than C57BL/6J mice to approach and follow SV mice (Fisher LSD tests: $p s=0.001)$. In C57BL/6J mice, stress produced an increased number of first order events as approach (d2: $H=16.49, d f=$ 3, $p<0.001$; Mann-Whitney, $p=0.002$ ) and follow behaviors (d3: $H=12.65, d f=3, p=0.005$; Mann-Whitney, $p=0.004$ ). Follows behaviors also lasted longer after stress (d3: stress effect
$F_{(1,31)}=9.96, p=0.004$, Fisher LSD test $p<0.001$. In $\beta 2^{-/-}$ mice, almost no significant changes in both number and total time of these first order events were observed after stress, with the exception of decreased in $d 1$ number $(H=9.99, d f=3$, $p=0.019$; Mann-Whitney, $p=0.026)$, and decreased duration of d2 [stress effect $F_{(1,31)}=7.88, p=0.009$, Fisher LSD Method, $p=0.002]$.

Concerning the second order events (d4, d5), no genotype effect $\left[F_{(1,31)}=0.25, p=0.62, \mathrm{NS}\right]$, no stress* genotype interaction $\left[F_{(1,34)}=2.52, p=0.12\right.$, NS], nor stress effect $\left[F_{(1,31)}=3.16, p=0.085, \mathrm{NS}\right]$ were found for $\mathrm{d} 4$ number. No stress* genotype interaction $\left[F_{(1,34)}=1.15, p=0.29, \mathrm{NS}\right]$ but a global stress effect $\left[F_{(1,31)}=8.73, p=0.006\right]$ for the total time of $\mathrm{d} 4$ event were detected. Also, for similar number, SV mice spent less time to escape a $\beta 2^{-/-}$mouse than a C57BL/6J mouse after contact ( $\mathrm{d} 5: H=10.58, d f=3, p=0.014$; Mann-Whitney, $p=0.04)$. Exposing C57BL/6J mice to stress significantly reduced the total time of this $\mathrm{d} 5$ event $(H=10.58, d f=3, p=0.014$; Mann-Whitney, $p=0.003$ ) while stress had no effect in $\beta 2^{-/-}$ mice.

Finally, the third order events d6 was only affected in C57BL/6J mice after stress. In these mice, stress produced a decreased of d6 number $(H=9.35, d f=3, p=0.025$; Mann-Whitney, $p=0.005)$ and reduced the total time of this events $(H=8.82$, $d f=3, p=0.032$; Mann-Whitney, $p=0.019$ ). No changes in both number and total time of this third order dynamic event were observed in $\beta 2^{-/-}$mice after stress.

For all groups, d2 events (Supplementary Figure 3) increased in the first minute of the task, earlier and more in not stressed mice of both genotypes than in stressed ones. In contrast, d6 events (Supplementary Figure 3), highly variable between individuals, were more robustly observed in not stressed mice than in stressed animals. With stress, this complex event drastically decreased and may disappear overtime. The near-loss of complex $\mathrm{d} 6$ event after stress in C57BL/6J mice could be explained by the drastic drop of $\mathrm{d} 4$ and $\mathrm{d} 5$ events. In $\beta 2^{-/-}$mice, it could be linked to the decrease of the simpler event $\mathrm{d} 2$.

The only difference between C57BL/6J and $\beta 2^{-/-}$mice concerned the first order events (approaches and follow behaviors) that were more numerous and lasted longer in $\beta 2^{-/-}$animals. In $\mathrm{C} 57 \mathrm{BL} / 6 \mathrm{~J}$ mice, acute stress led to an increase in first order events and to a decrease in second and third ones indicating a reduction in the complexity of behavioral sequences in this strain. In $\beta 2^{-/-}$mice, stress did not alter the second and third order events but reduced and therefore normalized first order events such as approaches and escapes (Table 1). Results obtained from chronogram analyses further highlighted that stress in C57BL/6J mice touched complex second order events while it altered more simple first order events in $\beta 2^{-/-}$mice. Thus, stress altered distinct complex behavioral classes in C57BL/6 and $\beta 2^{-/-}$mice.

\section{Stop events during social interaction (Figure 5, Table 1)}

The number of stop events of SV mice (e1) was unaffected by the genotype $\left[F_{(1,31)}=1.95, p=0.17\right.$, NS $]$ or the emotional status [stress effect: $F_{(1,31)}=0.013, p=0.91$, NS] of the IH mice. No stress*genotype interaction $\left[F_{(1,34)}=\right.$ 

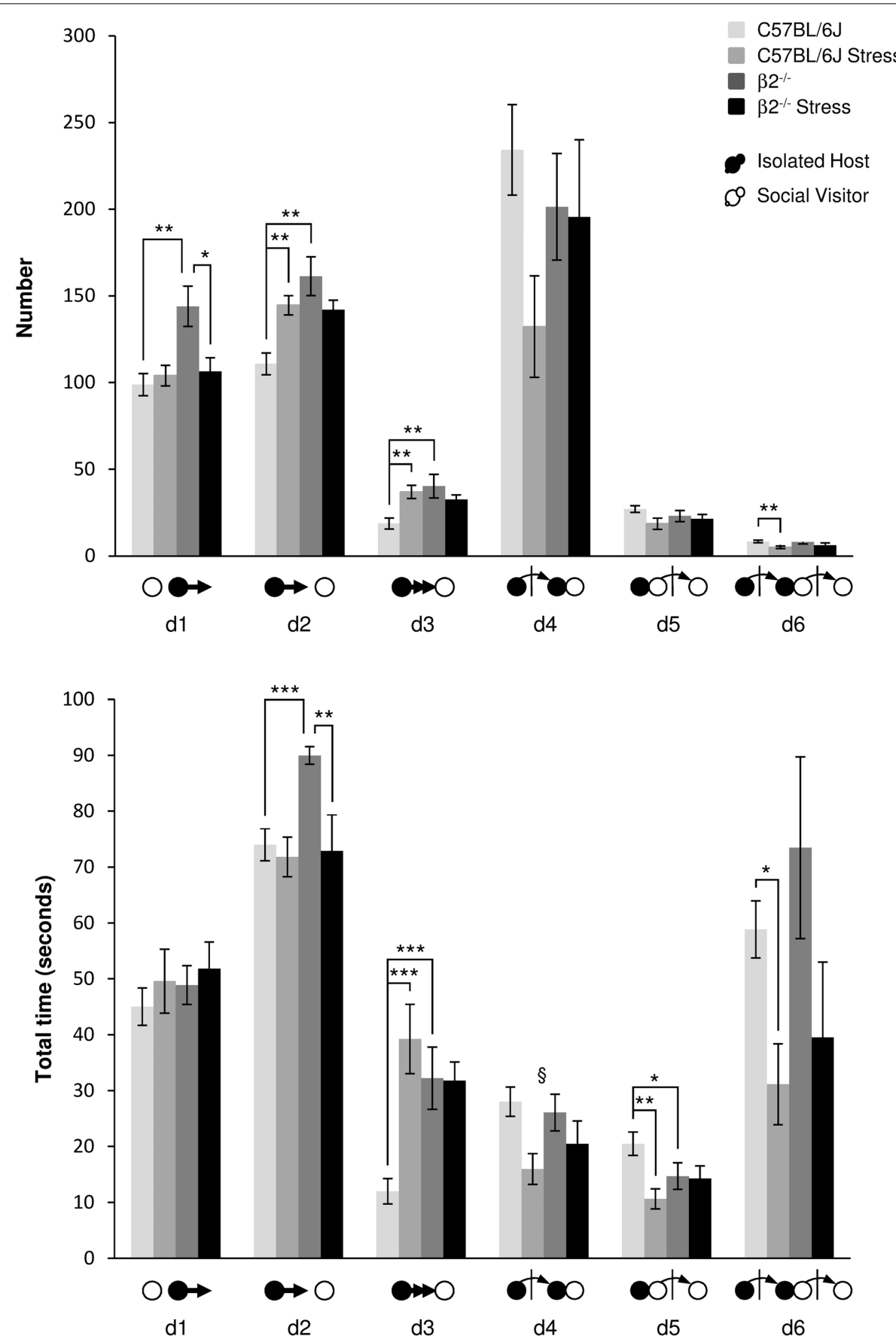

FIGURE 4 | Dynamic events during social interaction: events initiated by the Isolated Host mouse. The number (Top) and the total time (Bottom) of the dynamic events ( $d 1$ to $d 6$ as referred in Table 1 and Supplementary Table 1) were quantified during the 4 min of the social interaction task. IH mice were submitted or not to an acute stress (C57BL/6J: $n=11 ; \beta 2^{-/-}: n=9 ;$ C57BL/6J Stress: $n=8 ; \beta 2^{-/-}$Stress: $n=7)$. Data are expressed as means \pm SEM. ${ }^{*} p \leq 0.05, * * p \leq 0.01$, *** $p \leq 0.001,{ }^{\S}$ Stress effect $p=0.006$
$0.071, p=0.79$ ] was found. However, SV animals stopped for shorter time in presence of a stressed vs. a not stressed C57BL/6J mouse $(H=13.36, d f=3, p=0.004$; Mann-Whitney, $p<0.001)$.

For similar duration, no genotype effect was detected in the number of IH stop events (e2) between C57BL/6J and $\beta 2^{-/-}$mice
$\left[F_{(1,31)}=2.21, p=0.15\right.$, NS $]$ but a significant stress*genotype interaction was found $\left[F_{(1,34)}=7.97, p=0.008\right]$. The number of IH stop events increased after stress in $\beta 2^{-/-}$mice (Fisher LSD Method, $p=0.032$ ) but remained unchanged in C57BL/6J animals. In addition, stressed $\beta 2^{-/-}$made significantly more stop events than stressed C57BL/6J (Fisher LSD Method, 

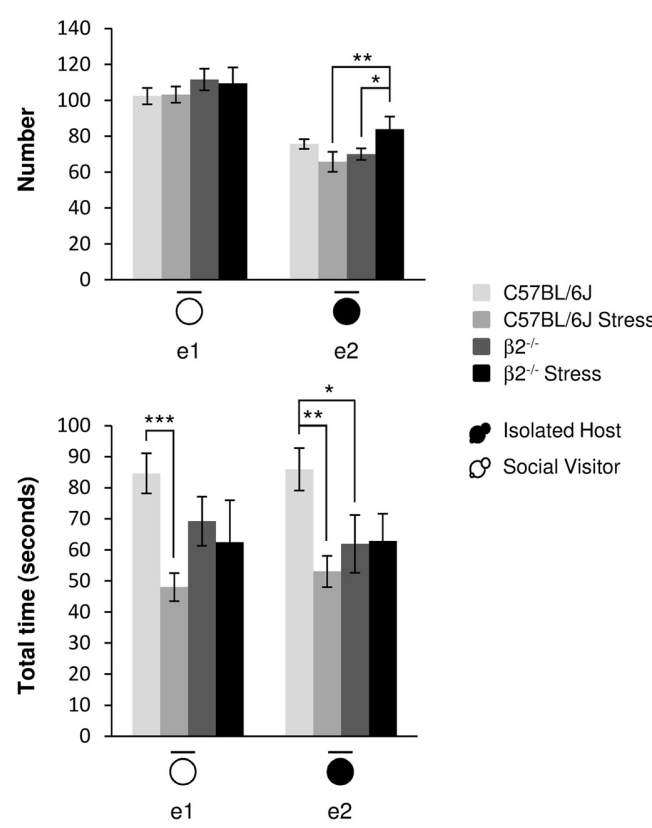

$\beta 2^{-/-}$Stress

- Isolated Host Social Visitor

Chronograms and density graphs of 1 and $e 2$ events
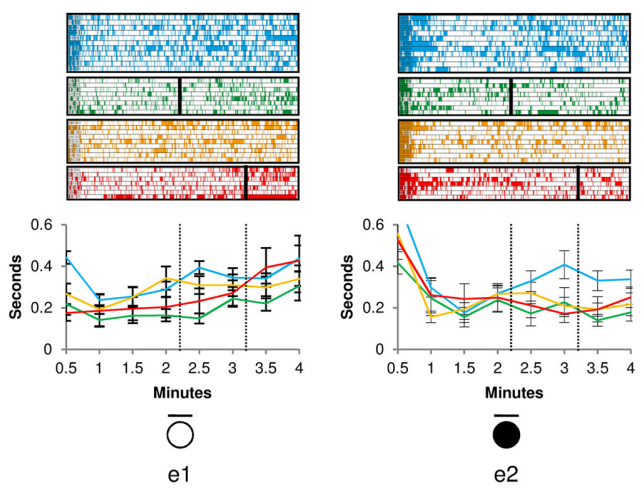

C57BL/6J C57BL/6J Stress $\quad \beta 2^{-/} \quad \beta 2^{-/-S t r e s s}$

FIGURE 5 | Stop events during social interaction. The number (Top) and the total time (Bottom) of stop events of $\mathrm{IH}$ and SV mice in the dyads were quantified during the $4 \mathrm{~min}$ of the social interaction task. e1: SV stop events; e2: IH stop events. IH mice were submitted or not to an acute stress. For each group, a corresponding number of SV mice was analyzed. Data are expressed as means \pm SEM. ${ }^{*} p \leq 0.05,{ }^{* *} p \leq 0.01,{ }^{* * *} p \leq 0.001$. Chronograms and density graphs (bottom) illustrated the temporal evolution of the aforementioned e 1 and e 2 events throughout the 4 min of the experiment. In the chronograms, each line represents stop events of an individual in a specific group. The length of each point is proportional to the duration of events. In the graphs, each line represented the mean of the temporal evolution of a given event for each group of mice. Vertical lines on chronograms and density graphs indicated the average latency to first attack in stressed $\mathrm{C} 57 \mathrm{BL} / 6 \mathrm{~J}$ and stressed $\beta 2^{-/-}$mice (full and dotted lines). C57BL/6J: blue, $n=11$; C57BL/6J Stress: green, $n=8 ; \beta 2^{-1-}$ : yellow, $n=9 ; \beta 2^{-/}$Stress: red, $n=7$.

$p=0.008)$. Also, for similar numbers, no genotype effect was detected between $\mathrm{C} 57 \mathrm{BL} / 6 \mathrm{~J}$ and $\beta 2^{-/-}$mice for e2 stop events duration $\left[F_{(1,31)}=0.93, p=0.34, \mathrm{NS}\right]$. A stress* genotype interaction $\left[F_{(1,34)}=5.36, p=0.027\right]$ and a stress effect $\left[F_{(1,31)}=\right.$
4.72, $p=0.037]$ were found. Stop events of IH mice were significantly lower in $\beta 2^{-/-}$mice as compared to C57BL/6J mice (Fisher LSD Method, $p=0.018$ ). C57BL/6J mice exposed to an acute stress also spent less time at rest than non-stressed mice (Fisher LSD Method, $p=0.002$ ).

Event $\mathrm{el}$ increased in the first minute of the task in not stressed mice and in the last minute in stressed ones. In contrast, e2 event drastically decreased after the first minute of the task to remain steadily low in all groups except in C57BL/6 J mice. This indicates that stop behaviors of the host mice were important feature of an organized and flexible social repertoire in $\mathrm{C} 57 \mathrm{BL} / 6 \mathrm{~J}$ mice and that they were compromised in animals exhibiting flexibility defects, whether $\beta 2^{-/-}$mice or stressed animals.

Thus, C57BL/6J mice spent more time at rest than $\beta 2^{-/-}$mice. Acute stress reduced this time in $\mathrm{C} 57 \mathrm{BL} / 6 \mathrm{~J}$ mice but had no effect in $\beta 2^{-/-}$animals. Also, SV mice spent less time at rest in presence of stressed C57BL/6J mice but not when facing a $\beta 2^{-/-}$mice (stressed or not). Thus, SV mice behavior was only influenced by C57BL/6J behavior.

\section{Dominance and aggressiveness during social interaction (Tables 1, 2)}

The number of paw control, on one hand, and of tail rattling and attacks, on the other hand, were manually quantified to respectively evaluate the dominance and the aggressiveness of $\mathrm{IH}$ mice during social interaction. SV mice never showed tail rattling and never attacked $\mathrm{IH}$ mice.

The number of paw control was significantly higher in $\beta 2^{-/-}$ mice than in C57BL/6J mice $(H=18.81, d f=3, p<0.001$; Mann-Whitney, $p<0.001)$ whereas tail rattling and attacks were absent in both genotypes. After stress exposure, and compared to their not stressed conspecifics, paw control significantly increased in C57BL/6J mice $(H=18.81, d f=3, p<$ 0.001 ; Mann-Whitney, $p=0.001$ ) but not in $\beta 2^{-/-}$mice. In contrast, both in $\mathrm{C} 57 \mathrm{BL} / 6 \mathrm{~J}$ and $\beta 2^{-/-}$mice, acute stress induced a significant increase in the number of tail rattling $(H=17.55$, $d f=3, p<0.001$; Mann-Whitney, $p=0.001$ for C57BL/6J mice, $p=0.015$ for $\beta 2^{-/-}$mice $)$and attacks $(H=19.92, d f=3$, $p<0.001$; Mann-Whitney, $p=0.001$ for C57BL/6J mice, $p=$ 0.005 for $\beta 2^{-/-}$mice). The range of tail rattling numbers was comprised between 0 and 25 in stressed C57BL/6J mice and between 0 and 35 in stressed $\beta 2^{-/-}$mice while the number of attack was comprised between 0 and 15 in stressed $\mathrm{C} 57 \mathrm{BL} / 6 \mathrm{~J}$ mice and between 0 and 28 in stressed $\beta 2^{-/-}$ mice. Even though quantitative expression of aggression varied individually, a large majority of mice exhibited aggressive behavior after stress whatever their genotypes (Supplementary Table 2). In addition, latency to first attack from stressed C57BL/6J mice was longer (in about $3 \mathrm{~min}$ ) but not significantly different than that stressed $\beta 2^{-/-}$animals (in about $2 \mathrm{~min}$ ).

Thus, restraint stress increased dominance only in C57BL/6J mice, and induced aggressiveness in both mouse genotypes. Aggressiveness was not due to previous mice isolation since it did not exist in not stressed mice. As such, it was imputable to stress and was independent of nicotinic system. 
Table 2 | Dominance and aggressiveness during social interaction.

\begin{tabular}{|c|c|c|c|c|}
\hline IH mice & C57BL/6J & C57BL/6J Stress & $\beta 2^{-/-}$ & $\beta 2^{-/-}$Stress \\
\hline \multicolumn{5}{|l|}{ NUMBER } \\
\hline Paw control & $5.45 \pm 0.98$ & $18.75 \pm 3.60^{* * *}$ & $15.56 \pm 2.84^{\dagger \dagger \dagger}$ & $19.29 \pm 4.09$ \\
\hline Attacks & 0.00 & $3.94 \pm 1.99 * * *$ & 0.00 & $9.07 \pm 4.35^{\ddagger \ddagger}$ \\
\hline \multicolumn{5}{|c|}{ LATENCY TO FIRST TAIL RATTLING (SECONDS) } \\
\hline $\mathrm{IH}$ mice & $240.00 \pm 0.00$ & $149.00 \pm 29.72 * * *$ & $240.00 \pm 0.00$ & $119.57 \pm 46.45^{\ddagger \ddagger}$ \\
\hline IH mice & $240.00 \pm 0.00$ & $169.63 \pm 22.14 * * *$ & $240.00 \pm 0.00$ & $132.71 \pm 41.80^{\ddagger \ddagger}$ \\
\hline
\end{tabular}

\section{Correlations between behavioral events during social interaction (Figure 6)}

Statistical correlations we performed to identify putative relationships between the different events of the mice social repertoire within each group of mice. Supplementary Figure 4 illustrated correlations for some key events and Figure $\mathbf{6}$ showed all significant statistical correlations.

With C57BL/6J mice, SV mice actions did not participate in the generation of contact or complex events (I). This data suggested that the host mouse was the principal actor in the dyad as it generated most contacts and was dominant. In addition, it showed that dominance ("paw") was associated with high sociability (i.e., various types of contact, approach, escape). After stress, most social relationships in C57BL/6J mice were broken while behavioral correlates of dominance diminished (II). Social organization in $\beta 2^{-/-}$mice appeared totally different (in particular for contact events) and reduced compared to C57BL/6J mice with dominance totally disconnected from social behavior except from follow behavior (III). After stress, an impoverishment and a marked fragmentation of social behavior in $\beta 2^{-/-}$mice appeared (IV).

Thus, we evidenced drastic differences in the arrangement of social events between $\mathrm{C} 57 \mathrm{BL} / 6 \mathrm{~J}$ and $\beta 2^{-/-}$mice. Acute stress deconstructed the links existing between the different events of a given behavioral class and between the various classes of the social repertoire in both genotypes. This occurred even if there is no quantitative difference in the social repertoire and in the emergence of aggressiveness in stressed C57BL/6J and stressed $\beta 2^{-/-}$ mice (Table 1). In addition, although dominance normally exists in both C57BL/6J and $\beta 2^{-/-}$not stressed animals, its value and consequences were only modified after stress in C57BL/6J mice.

\section{Behavioral transitions during social interaction (Figure 7)}

Transition graphs were built to investigate how the various events fit together during the social interaction task. They represent the probability of a given event to be preceded or followed by one or several events and provide complementary information from quantitative data. Indeed, d3 event, poorly represented in number or time in all groups (Figure 4), will appear to be crucial to trigger behavioral strings (see below). From the repertoire previously described (Supplementary Table 1), the key behavioral events participating to the dyads actions were contact (a1, a2, a3, and a4), relative position (b1 and b2), follow (d3), stops (e1, e2) and dynamic (d6) events.

Common transitions to all groups of mice (Figure 7A). As shown in Figure 7A, dyads of all groups shared multiple sequences of action. In addition, the majority of social behaviors displayed a repetitive pattern (i.e., high probability to occur at least twice successively) suggesting a strong value for the given behavior.

In all groups, stops of the SV mouse (e1, black arrows) triggered all main contacts, postures, and dynamic events of the dyads. It suggested that stops of the SV mouse triggered fixed behaviors whatever the IH mouse it faced. This occurs even if SV mice spent less time at rest in presence of a stressed than a not stressed C57BL/6J mouse (Figure 5, e1, bottom). In contrast, all IH mice shared 2 behaviors initiating other behavioral sequences: stops (e2) and follow behaviors (d3) (brown arrows). The event e2 had two main consequences, e1 (SV stops) and b1 (SV in front of $\mathrm{IH}$ ) while $\mathrm{d} 3$ event had three major consequences, both IH and SV stops (e1 and e2) and oral-genital contacts (a3).

SV mice were always C57BL/6J group-housed not stressed mice. Therefore, independently of the genotype or the emotional status of the social partner, common transitions between key behavioral events were centered on stops of the SV mice. Moreover, host mice from the different groups, which were always previously isolated and habituated to the environment, shared two key behavioral events: stops and follow behaviors.

In addition to common transitions described above, the different groups of mice share or not some transitions (see below).

Effect of genotype (comparisons between C57BL/6J and $\beta 2^{-/-}$ mice Figure $7 \boldsymbol{B}$ ). Some sequences were observed both in $\mathrm{C} 57 \mathrm{BL} / 6 \mathrm{~J}$ and in $\beta 2^{-/-}$mice (black arrows) while others were specific either to $\mathrm{C} 57 \mathrm{BL} / 6 \mathrm{~J}$ (blue arrows) or to $\beta 2^{-/-}$mice (yellow arrows).

C57BL/6J stop events (e2) triggered close contact (a1), relative position (b2), and follows (d3) events. In contrast, stop events 


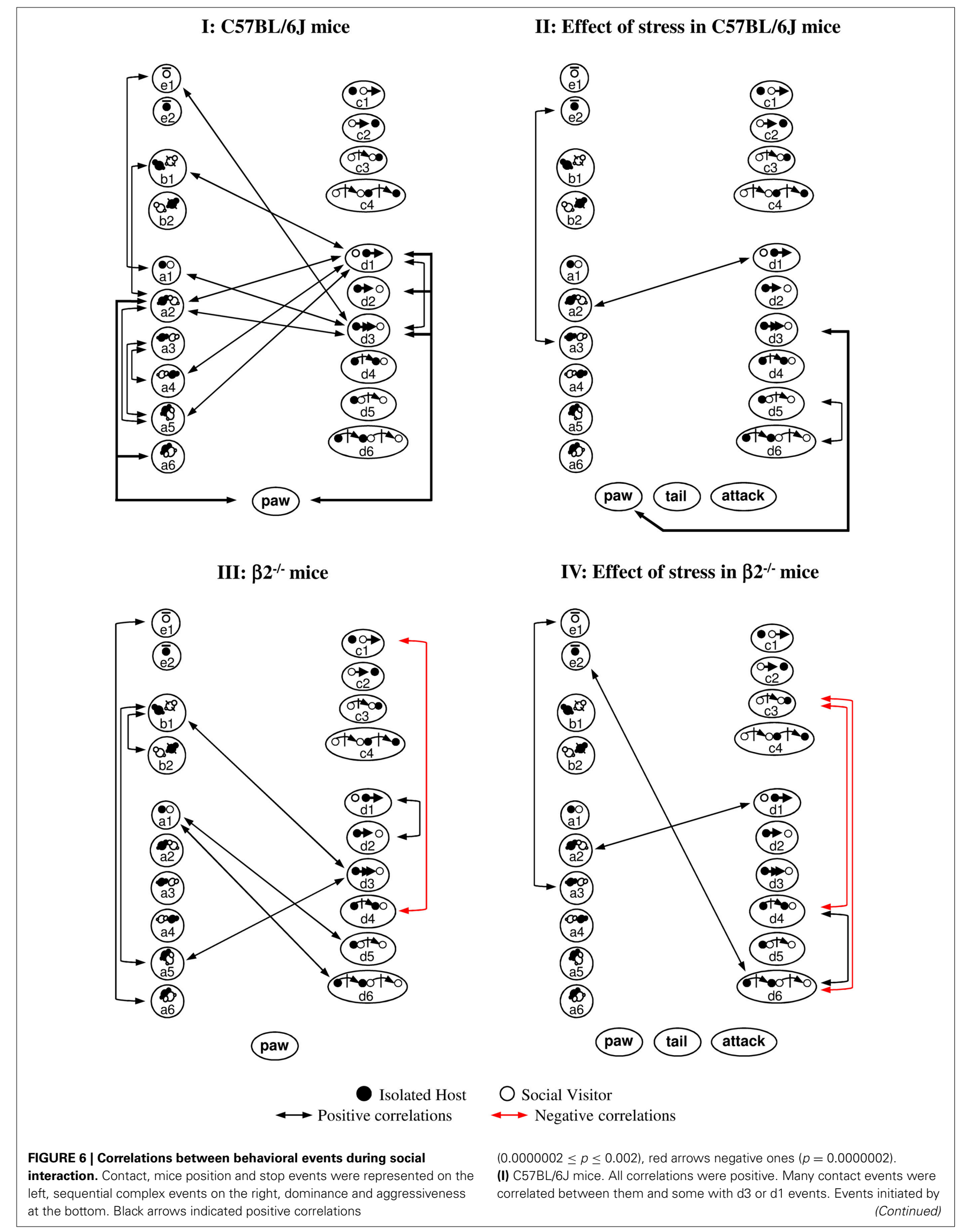




\section{FIGURE 6 | Continued}

C57BL/6J mice were interrelated (d3-e1; d3-d1). Social dominance was correlated to many events (see also Supplementary Figure 4I). (II) Effect of stress in C57BL/6J mice. Very few correlations were detected in stressed C57BL/6J mice. Contact events became almost completely disconnected from follow and escape behaviors. Paw control, more exhibited by C57BL/6 stressed animals (Tables 1, 2), became only linked with follow behaviors (d3, see also Supplementary Figure 4I). Although aggression-like behaviors emerged, no correlation with any social or dominance events were detected. (III) $\beta 2^{-/-}$mice. Compared to C57BL/6J mice, contact events were not interrelated anymore. Correlations within other behavioral categories appeared. Follow events became interrelated with a5 and b1 events (see also
Supplementary Figure 4II). Even if paw control was significantly more abundant in $\beta 2^{-/-}$mice than in C57BL/6J mice (Tables 1, 2), this index of dominance was not correlated with any event. (IV) Effect of stress in $\beta 2^{-/-}$ mice. All correlations observed in $\beta 2^{-/-}$mice disappeared after stress while some other positive ones emerged (see also Supplementary Figure 4III) Follow behaviors, not quantitatively modified by stress (Figure 4) became disconnected from all events. All index of dominance and aggression correlated with none behavioral events in the stressed $\beta 2^{-/-}$mice social repertoire even if tail rattling and aggression drastically increased (Table 2). See Supplementary Table 1 for behavioral symbols. Correlations were taken into account for $p \leq 0.0022$. C57BL/6J: $n=11 ; \beta 2^{-/-}: n=9 ; \mathrm{C} 57 \mathrm{BL} / 6 \mathrm{~J}$ Stress: $n=8 ; \beta 2^{-/}$Stress: $n=7$. of $\beta 2^{-/-}$mice (e2), which lasted significantly less than that of C57BL/6J mice (Figure 5), only induced oral-genital contacts (a3 and $\mathrm{a} 4)$.

Thus, stop events played a crucial role in the initiation of numerous different behaviors in $\mathrm{C} 57 \mathrm{BL} / 6 \mathrm{~J}$ mice. In contrast, follow behaviors appeared to play a fulcrum role in $\beta 2^{-/-}$ animals.

Effect of stress in C57BL/6 J mice (Figure 7C). Both stressed and not stressed $\mathrm{C} 57 \mathrm{BL} / 6 \mathrm{~J}$ mice shared some sequences indicating that they are independent of the emotional status of the mice (black arrows).

In C57BL/6J mice, long sequences existed, while acute stress induced shorter ones. In not stressed mice, stop events (e2) triggered several sequences (blue arrows) while in stressed mice, e2 event which lasted significantly less than in C57BL/6J mice (Figure 5), induced only one (green arrows). This is in concordance with the aforementioned key role of e 2 event in not stressed C57BL/6J mice. This important e 2 fulcrum is almost abolished by stress.

Interestingly, some strings only observed after stress in C57BL/6J animals existed in $\beta 2^{-/-}$mice. Also, d3 event in stressed C57BL/6J mice appeared crucial to initiate behavioral sequences as seen for $\beta 2^{-/-}$mice. Thus, these results complemented our quantitative data showing some similarities of social behavior between stressed $\mathrm{C} 57 \mathrm{BL} / 6 \mathrm{~J}$ and not stressed $\beta 2^{-/-}$mice.

Overall, acute stress shortened behavioral sequences in C57BL/6J mice and dramatically triggered aggressive behaviors (Table 2). Moreover, the social repertoire partially shared by $\mathrm{C} 57 \mathrm{BL} / 6 \mathrm{~J}$ after stress mice and $\beta 2^{-/-}$mice supported the idea of a close behavioral organization in the two groups.

Effect of stress in $\beta 2^{-/-}$mice (Figure $7 D$ ). $\beta 2^{-/-}$and $\beta 2^{-/-}$ stressed mice shared some sequences that are likely to reflect the core of the $\beta 2^{-/-}$social repertoire (black arrows). These common transitions were more numerous than in stressed and not stressed $\mathrm{C} 57 \mathrm{BL} / 6 \mathrm{~J}$ mice, reinforcing a more rigid behavior in $\beta 2^{-/-}$mice than C57BL/6J mice.

Some transitions observed in stressed and not stressed $\beta 2^{-/-}$ mice existed in stressed C57BL/6J mice (Figure 7C) while some transitions appearing after stress in $\beta 2^{-/-}$mice existed in stressed and not stressed C57BL6 mice. Additional sequences, seen in C57BL6 stressed mice appeared after stress in $\beta 2^{-/-}$mice while others disappeared. These results were in concordance with our quantitative analysis showing similar data between C57BL6 and $\beta 2^{-/-}$mice after stress (Table 1). In addition, stress diminished the crucial role of e2 event in $\beta 2^{-/-}$mice as partially seen in C57BL6 mice for which e2 event triggered no sequences, aside from that shared by all groups (Figure 7A).

Overall, acute stress in $\beta 2^{-/-}$mice induced behavioral transitions common to the C57BL6 strain or specific to all stressed animals. These data and quantitative results (see Table 1) support the idea that after acute stress, social behavior of $\beta 2^{-/-}$mice acquired C57BL/6J features.

Effect of stress in C57BL/6J and in $\beta 2^{-/-}$mice (Figure 7E). All stressed mice shared most transitions (black arrows) while very few transitions differed between stressed C57BL/6J (green arrows) and stressed $\beta 2^{-/-}$animals (red arrows). Interestingly, acute stress induced in all mice shrinkage of behavioral transitions as evidenced by correlation analyses. After stress, behavioral sequences in both mouse genotypes tend to be similar in coherence with the quantitative results showing no statistical difference in the behavioral repertoire, dominance and aggressiveness between stressed $\mathrm{C} 57 \mathrm{BL} / 6 \mathrm{~J}$ and stressed $\beta 2^{-/--/-}$mice (Tables 1, 2).

\section{Plasma corticosterone levels (Table 3)}

Plasma corticosterone levels were measured as described in Supplementary Figure 1. Statistical analyses showed a significant group effect $(H=27.17, d f=7, p<0.001)$. Mann-Whitney tests further revealed no significant genotype effect in condition A (measures performed $60 \mathrm{~min}$ after mice transfer from animal facility, $p=0.69$ ), in condition $\mathrm{B}$ (measures performed immediately after stress, $p=0.13$ ), and in condition $C$ (measures performed after exploration) for stressed $(p=0.67)$ and not stressed mice $(p=0.29)$. In contrast, whatever the mice genotype, not stressed animal showed significant increases in plasma corticosterone levels in condition $\mathrm{C}$ compared to condition $\mathrm{A}\left(p=0.01\right.$ in $\mathrm{C} 57 \mathrm{BL} / 6 \mathrm{~J}$ mice and $p=0.006$ in $\beta 2^{-/-}$ mice). Also, a significant stress effect was observed when comparison were performed between conditions $\mathrm{A}$ and $\mathrm{B}(p s=0.01$ in both $\mathrm{C} 57 \mathrm{BL} / 6 \mathrm{~J}$ and $\beta 2^{-/-}$mice) or between conditions $\mathrm{A}$ and $\mathrm{C}\left(p=0.006\right.$ in $\mathrm{C} 57 \mathrm{BL} / 6 \mathrm{~J}$ mice and $p=0.007$ in $\beta 2^{-/-}$mice $)$. Finally, a significant decreased was detected in $\beta 2^{-/-}$mice at the end of the exploration (comparison conditions $\mathrm{C}$ vs. $\mathrm{B}, p=$ 0.02 ). Thus, whatever the mice genotype and its emotional status (stressed or not), corticosterone levels measured after exploration 
A

Isolated Host

Social Visitor

$\rightarrow$ Transitions from SV $\longrightarrow$ Transitions from IH
Common transitions to all groups of mice

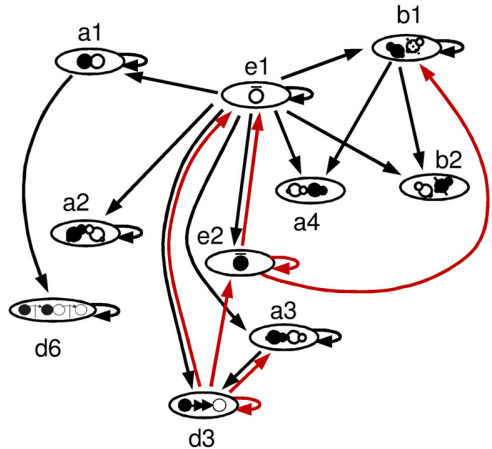

B

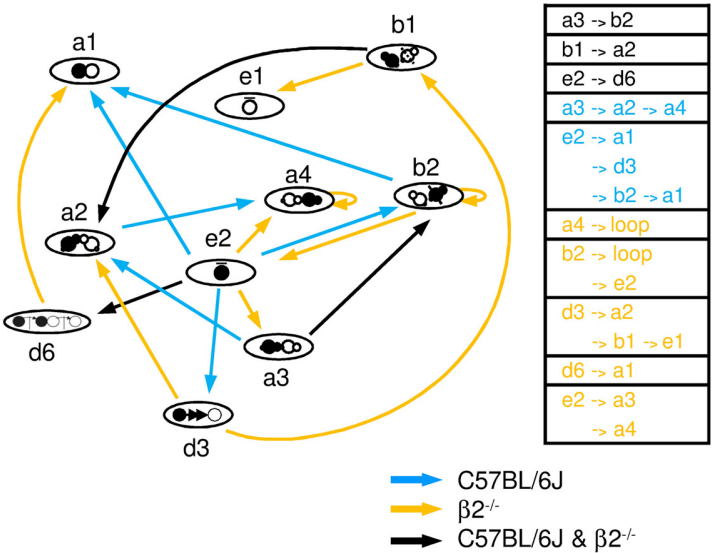

D

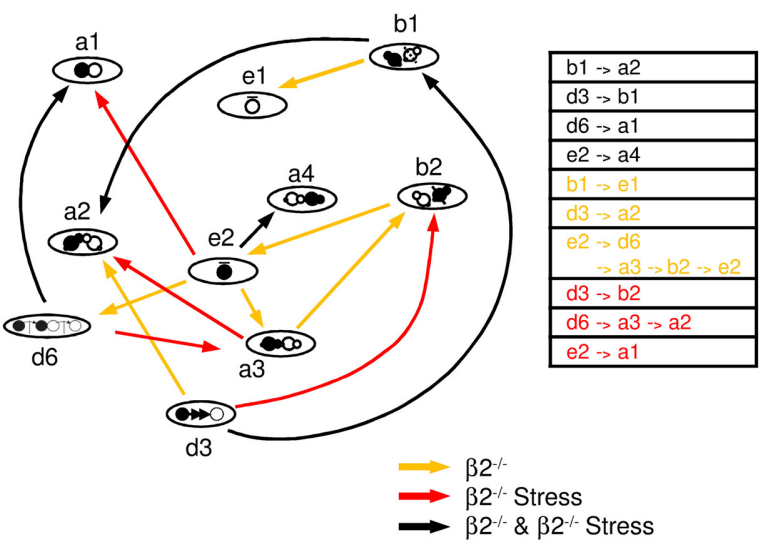

C Effect of stress in C57BL/6J mice

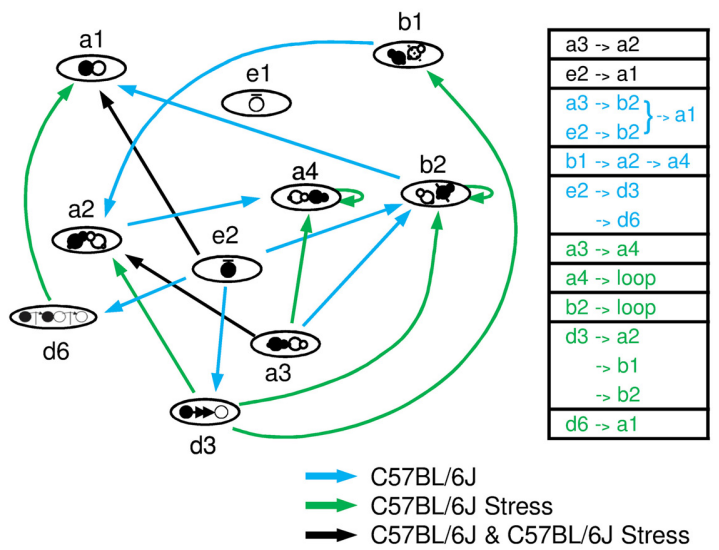

E Effect of stress in C57BL/6J and $\beta 2^{-/-}$mice

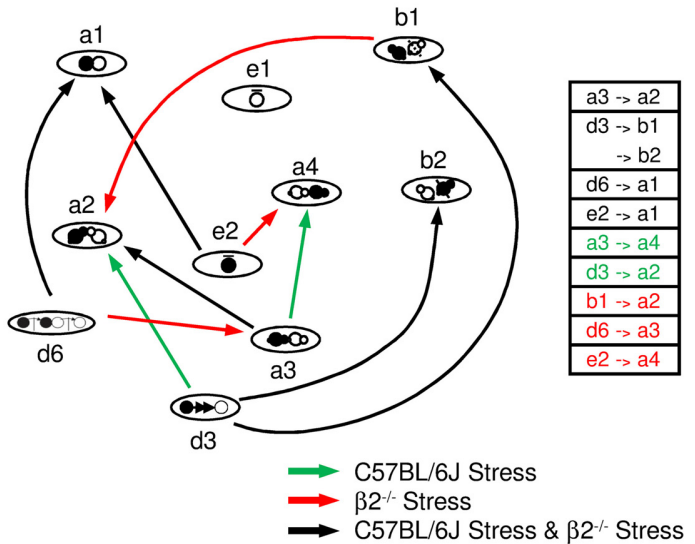

(blue arrows) and C57BL/6J stressed mice (green arrows). (D) Effect of stress in $\beta 2^{-/-}$mice: common (black arrows) and specific transitions to $\beta 2^{-/-}$(yellow arrows) and $\beta 2^{-/-}$stressed mice (red arrows). (E) Effect of stress in C57BL/6J and $32^{-/-}$mice: common (black arrows) and specific transitions to $\mathrm{C} 57 \mathrm{BL} / 6 \mathrm{~J}$ stressed (green arrows) and $\beta 2^{-/-}$stressed mice (red arrows). Tables next to each figure summarized the common and the specific transitions of each group of mice. See Supplementary Table 1 for significance of the symbols. 
Table 3 | Plasma corticosterone levels $(\mu \mathrm{g} / \mathrm{dl})$ in different experimental conditions.

\begin{tabular}{lccc}
\hline Mice & Condition A & Condition B & Condition C \\
\hline C57BL/6J & $1.21 \pm 0.48$ & & $12.73 \pm 0.98^{\dagger \dagger}$ \\
C57BL/6J Stress & & $13.42 \pm 2.42^{*}$ & $11.85 \pm 1.79^{* *}$ \\
$\beta 2^{-/-}$ & $1.11 \pm 0.79$ & & $10.23 \pm 1.72^{\dagger \dagger}$ \\
$\beta 2^{-/-}$Stress & & $20.10 \pm 2.75^{*}$ & $13.55 \pm 1.66^{* *}$, $^{\ddagger}$
\end{tabular}

Blood samples were collected in three different experimental conditions: condition A, 60 min after mice exit from animal facility ( $n=4$ for each genotype); condition $B$, after stress ( $n=6$ for each genotype), and condition $C$, after the exploration period (C57BL/6J mice: $n=6$ not stressed, $n=7$ stressed; $\beta 2^{-1-}$ mice: $n=7$ not stressed, $n=9$ stressed). Values are means \pm SEM. Effects of stress within genotype: ${ }^{*} p=0.01,{ }^{* *} p \leq 0.007$. Effect of condition within genotype in not stressed ( $\left.{ }^{H t} p=0.01 ;{ }^{H T} p=0.006\right)$ and stressed mice $\left.{ }^{\ddagger} p=0.02\right)$.

(condition C) were higher than those measured at the exit of the animal facility.

\section{DISCUSSION}

The present study was performed to determine the immediate impact of acute restraint stress on social interactions in adult male mice and to investigate the contribution of neuronal nicotinic receptors (nAChRs) in these effects. C57BL/6J mice were used, because they were known to exhibit high sociability (Sankoorikal et al., 2006) and are largely used by the Neuroscience community. $\beta 2^{-/-}$mice which constitutively lack nAChRs were used because they expressed less behavioral flexibility in social contexts (Granon et al., 2003; Besson et al., 2008).

\section{CORE SOCIAL BEHAVIORS INDEPENDENT OF GENOTYPE AND STRESS STATUS}

We found that, in all 4 types of dyads, SV stops always occurred at the starting point of contact events, postures, or dynamic event, regardless of the emotional status or genotype of its partner. In addition, for all dyads, IH stops and follow events were key points in the social repertoire.

\section{EXHAUSTIVE ANALYSIS: BEHAVIORAL SIMILARITIES AND DIFFERENCES IN C57BL/6J AND $\beta \mathbf{2}^{-/-}$MICE}

We first confirmed here previous data as $\beta 2^{-/-}$mice made longer contacts and more numerous follows, spent less time at rest and were more dominant (Granon et al., 2003; Maubourguet et al., 2008; de Chaumont et al., 2012; Coura et al., 2013). We also confirmed that key events, crucial for initiating various behaviors, differed between the two mouse genotypes. We thus explored thoroughly their social consequences in both genotypes. We found that $\beta 2^{-/-}$mice exhibited a strong and constant interest for contacting their social partner as the experiment progressed while C57BL/6J animals, decreasing their interests for social contact, became accustomed to the social situation over time (Supplementary Figure 2). Furthermore, follows in $\beta 2^{-/-}$mice were only correlated with oral-oral contact and posture behind the SV mouse while they were correlated with various actions (contacts, escape, dominance) in C57BL/6J mice (Figure 6). This indicated that follows are associated to a restricted social repertoire in $\beta 2^{-/-}$mice but to a large panel of behavior with no fixed consequences in C57BL/6J. Also, correlation analyses showed no links between different contact subtypes in $\beta 2^{-/-}$mice while many of them were related in C57BL/6J animals (Figure 6). Stop events allowed mice to scan their environment and to acquire and evaluate information about potential risks (Quartermain et al., 1996; Maubourguet et al., 2008). We showed here that their relative absence in $\beta 2^{-/-}$mice, consistent with their hyperactivity (Avale et al., 2008), had strong consequences on the social repertoire: in $\beta 2^{-/-}$mice, stop events only induced oralgenital contacts while in $\mathrm{C} 57 \mathrm{BL} / 6 \mathrm{~J}$ mice, stop events triggered multiple events, including contacts, relative position events, and follows (Figure 7). All these data reinforced the fact that $\beta 2^{-/-}$ mice exhibited less flexible behavior than C57BL/6J and showed more stereotyped and restricted actions (Granon et al., 2003; Maubourguet et al., 2008; de Chaumont et al., 2012). It also showed that the behavioral repertoire may be possessed by both genotypes but may not have the same "value."

We revealed a crucial importance of dominance behaviors: in C57BL/6J mice dominance was associated with a large panel of social contact but this was not the case in $\beta 2^{-/-}$mice, for which dominance seemed an isolated compound (Figure 6), although quantitatively over represented (Table 2 ). This data matched with our previous findings, which showed that dominance tendencies were strongly modulated by the nicotinic-cholinergic system (Coura et al., 2013). For the first time, we showed that behavioral differences between $\mathrm{C} 57 \mathrm{BL} / 6 \mathrm{~J}$ and $\beta 2^{-/-}$mice were not due to different plasma corticosterone levels, either measured in a control condition ( $60 \mathrm{~min}$ after exit from animal facility), or after exploration of the novel environment. Baseline measures were very low, in agreement with others results (Thoeringer et al., 2007). This showed that animal isolation per se did not generate a chronic stress. However, as compared to baseline values, novelty exploration increased corticosterone in all not stressed animals (Table 3), as had been reported by others in C57BL/6J animals (Roozendaal, 2002; Chauveau et al., 2010; Beerling et al., 2011; Chaouloff and Groc, 2011), showing that exploration of a novel environment induced activation of physiological parameters normally associated to stress responses (De Boer and Van der Gugten, 1987; Beerling et al., 2011). Besides, we detected that both mouse genotypes similarly and largely preferred to be behind SV mice all along the experiment. In contrast, the opposite posture gradually appeared more often over time, particularly in C57BL/6J mice (Figure 2). These findings can be explained by the fact that SV mice were always C57BL/6J, group-housed, not stressed and never dominant in our experimental condition. Indeed, it was shown that taking place behind a partner is a posture likely to be exhibited by dominant animals (Arakawa et al., 2007). Thus, our results suggested that relative positions events in this task could be used as an index of a mouse's tolerance to another mouse.

In summary, the present study showed that each mouse genotype exhibited a specific complex social behavioral pattern and developed distinct social strategies. It highlighted major behavioral difference between $\mathrm{C} 57 \mathrm{BL} / 6 \mathrm{~J}$ and $\beta 2^{-/-}$mice, hence the important role of the cholinergic nicotinic system in the social strategy used by animals to organize their behavior. The 
differences between $\mathrm{C} 57 \mathrm{BL} / 6 \mathrm{~J}$ and $\beta 2^{-/-}$mice in this task may rely on a different trade-off between exploitation and exploration: C57BL/6J mice would favor exploration of various options, including social contact when confronted to a novel environment, and $\beta 2^{-/-}$mice would favor exploitation of the social reinforcement. Favoring exploitation over exploration has been shown to be accompanied by rigid behaviors (Cohen et al., 2007). This view is consistent with the involvement of the monoaminergic ascendant system on one hand and of the cholinergic system on the other hand in the governance of the balance between exploration and exploitation (Cohen and Aston-Jones, 2005; Yu and Dayan, 2005). As the regulation of this balance has been shown fundamental for adaptive and flexible behaviors (Kehagia et al., 2010), our data supported the need for functional nAchRs in social context, complex, changing and uncertain by nature (for review, Cohen et al., 2007).

\section{STRESS EFFECTS IN C57BL/6J MICE}

Although SV mice were not subjected to stress procedure, it indirectly altered their behavior: it shorted their stops and their tolerance when facing a stressed C57BL/6J mouse, indicating that SV was influenced by the emotional status of its partner. This can be due to the increase of follows, dominance and aggressiveness exhibited by stressed mice. This adaptation to their social partner, in turn, deeply modified their entire social repertoire as seen in transition graphs. In another social paradigm (3 chambers), Yang et al. (2012) showed that C57BL/6J mice adjusted their behavior, depending on the genotype of their partner. Also, Varlinskaya et al. (1999) showed that adolescent rats changed their social behaviors depending on the social activity of their play partner, as observed in other species (for review, Blanchard et al., 2003) or in other social tasks (Nyberg et al., 2004; Moy et al., 2008; Fairless et al., 2013). However, this is the first study to report that such a profound, dynamic and rapid adaptation occurred in a dyad of adult mice that had never interacted before. Future studies should investigate how this adaptation might be achieved; it may involve communication, via acoustic (Panksepp and Lahvis, 2011; Chabout et al., 2013), olfactory (Arakawa et al., 2008a,b; Deschenes et al., 2012), visual (Clark et al., 2006), and/or tactile (Clark et al., 2006; Wolfe et al., 2011; Deschenes et al., 2012) cues (Adolphs, 2010; Silverman et al., 2010).

Stress had three main consequences in IH C57BL/6J mice: it impoverished the social repertoire, increased dominance, and fostered aggressive behaviors. The social impoverishment was illustrated by the reduction of complex sequences with concomitant increase in single events such as approaches and follows, the shortening of some contact events and of mutual tolerance (Table 1). Stress also reduced the duration of stop events that were shown to be keys in the decision process for making various social actions. In consequence, their impact on subsequent social behaviors was abolished (Figure 7). Therefore, by shortening the time spent scanning their environment during stops, stressed mice reduced the panel of their possible behavioral choices. Interestingly, such stress effect has also been reported in humans to promote habits (Schwabe and Wolf, 2009) and to reduce the panel of strategies during decision-making tasks (for review, Starcke and Brand, 2012). Also, we showed that follow behaviors increased after stress and appeared crucial for initiating multiple short sequences. Their consequences changed as compared to not stress condition: the relationships between contacts and follows were completely abolished by stress (Figure 6). These features were those observed in $\beta 2^{-/-}$mice without stress. As consequence, the complexity and the length of behavioral sequences were reduced in stressed C57BL/6J mice, and social behaviors appeared scattered and less fluently organized. Our data thus showed that the meaning of behaviors that are part of the normal social repertoire (e.g., follows) may depend on the emotional status of the animals. It implies that the gross measurement of their existence is not sufficient to characterize a social deficit in mice models.

We reported that single restraint stress increased dominant behaviors by more than three-fold in C57BL/6J mice, and dramatically altered their consequences. Social dominance is a normal behavior (Blanchard et al., 1984, 2003; Chichinadze et al., 2011). Without stress, dominance promotes social contacts whereas after stress, it favored only follows (Figure 6).

We showed that aggressiveness and dominance were dissociated social features that were never correlated, as previously reported (Coura et al., 2013). IH mice were isolated for 4 weeks prior to the experiments. It is questionable whether social isolation can itself promote aggression. To investigate this question, we compared our social task with other tasks studying aggressiveness. For example, in the resident-intruder task, classically used to trigger aggressiveness, social isolation is not the only component of the procedure: aggression is typically realized in the home cage of the isolated mouse and in some cases, males are previously exposed to females to increase territorial behavior, or are confronted with partners of a different size (Miczek and O’Donnell, 1978; Crawley, 2000; Miczek et al., 2001; Arregi et al., 2006; Neumann et al., 2010; Yohe et al., 2012; Marquez et al., 2013). In the present study, the task was never conducted in the home cage of a mouse. Also, the experimental cage was much larger than home cages, and it contained clean bedding; this environment favored novelty exploration and prevented strong territorial behavior as shown previously (Supplementary Figure 1 in Avale et al., 2011). Finally, our animals were never exposed to females. Therefore, our task differed dramatically from other tasks widely used to trigger aggressiveness. Moreover, we used C57BL/6J mice, which exhibit high sociability (Sankoorikal et al., 2006; Yang et al., 2012) and are generally not considered an aggressive strain (Puglisi-Allegra and Cabib, 1985; Roubertoux et al., 1999; Le Roy et al., 2000; Sankoorikal et al., 2006; de Chaumont et al., 2012), even after 8 weeks of social isolation (Puglisi-Allegra and Cabib, 1985). This non-aggressive disposition was confirmed in our study, because no aggression was observed in not stressed dyads. Thus, stress-induced aggressive behavior could not be attributed to the isolation of one of the adult mice in our experimental conditions. Also, in social contexts, aggression can be promoted by various experiences, including shocks (Puglisi-Allegra and Cabib, 1985), post-weaning isolation (Toth et al., 2011, 2012; Tulogdi et al., 2014), post-traumatic stress disorders (Lasko et al., 1994; Pavic et al., 2003; Haller et al., 2005), and early life stressful experiences (Veenema, 2009; Marquez et al., 2013). Prolonged or recurrent stress also contributed to aggressive behaviors (Wood 
et al., 2003; Yohe et al., 2012; Umukoro et al., 2013). To our knowledge, however, the present study was the first to assess aggressive behavior after delivering a single short stress to adult mice. As expected, immobilization stress increased plasma corticosterone levels. It is noticeable that plasma corticosterone levels remained steadily high when stress was followed by novelty exploration in $\mathrm{C} 57 \mathrm{BL} / 6 \mathrm{~J}$ mice. Therefore, our stress procedure did not superimpose to a putative isolation-induced stress.

Social experiments reported by others were mostly performed during the light phase of the cycle, although some experiments were conducted during the dark phase. However, it has been reviewed recently that sociability in rodents can be efficiently evaluated in the light phase (Yang et al., 2007, 2008). It is well known that plasma corticosterone has a circadian rhythm, with a peak around 3 p.m., a largest second one around 7 p.m., and a relatively high level during the first $6 \mathrm{~h}$ of night (De Boer and Van der Gugten, 1987; Kalsbeek et al., 1996). However, we cannot exclude that our experiments, conducted when plasma corticosterone levels were the lowest, could have led to different behavioral results if conducted in the dark phase of the cycle. In our experimental conditions, aggressiveness cannot be due to changes in plasma corticosterone levels induced by novelty exploration nor to the stress itself. Since social behaviors are supported by the HPA axis (for review, Owings and Coss, 2007), it may be involved, at least partially, in the stress responses observed here. But how the adaptive adjustment of behavioral system develops and evolves remains to be determined.

In conclusion, stressed C57BL/6J mice managed social contact with a novel social partner by reorganizing their behavior; moreover, they reduced or eliminated complex sequential behaviors. Interestingly, the dominance level in stressed C57BL/6J mice increased to the levels observed in $\beta 2^{-/-}$mice. This finding suggested that stress may alleviate behavioral inhibition mediated by the cholinergic system (Picciotto et al., 2012) or by the prefrontal monoaminergic systems (Arnsten, 2009; Ginsberg et al., 2011), because $\beta 2^{-/-}$mice exhibited constitutive major increases in the monoaminergic and cholinergic tones in the prefrontal cortex (PFC) (Coura et al., 2013). Previous studies showed that aggressiveness also resulted from lesions in the NA system (Cambon et al., 2010) or NA PFC depletion (Coura et al., 2013), and was associated with brain cholinergic and NA systems (Maxson, 2009; Ginsberg et al., 2011). Thus, the effects of stress in C57BL/6J mice may have been due to an acute increase in acetylcholine and/or monoamine PFC tone (Das et al., 2000; Del Arco and Mora, 2009; for review, Picciotto et al., 2012).

\section{STRESS EFFECTS IN $\beta 2^{-/-}$MICE}

Stressed $\beta 2^{-/-}$mice acquired C57BL/6J-like social behavior. That is, in $\beta 2^{-/-}$mice, stress drastically reduced social contacts to the levels observed in C57BL/6J mice, and it normalized approaches, escapes and the number of stops. However, stress had no effect on tolerance, follows, or complex behaviors. After stress, follows were totally disconnected from all behavioral events (Figure 6). This disconnection may contribute to the reduced contact durations observed after stress. Sequences initiated by stop events were restricted, thus behavioral complexity was reduced (Figure 7). Finally, stress induced no additional dominance, but boosted aggressiveness. Individual data on chronograms and temporal evolution curves showed that the occurrence of aggression did not trigger systematic changes in social events; thus, these behavioral features were independent. In addition, emergence of aggressive behaviors seemed incompatible with elaboration of complex social sequences (Figure 7). Exploration was not associated to additional increase in plasma corticosterone in stressed $\beta 2^{-/-}$ mice. On the contrary, we observed a significant decrease in this stress marker at the end of the exploration period, as compared to the one measured immediately after immobilization. Thus, as for $57 \mathrm{BL} / 6 \mathrm{~J}$ mice, aggressiveness cannot be due to increases in plasma corticosterone amount. After stress, plasma corticosterone in $\beta 2^{-/-}$mice tended to be higher (although this was not significant) than in $\mathrm{C} 57 \mathrm{BL} / 6 \mathrm{~J}$ mice. This suggested that $\beta 2^{-/-}$ mice may be more sensitive to restraint stress (physical discomfort) than to stress generated by novelty exploration. Thus, stress would induce a focus on the internal state rather than on external stimuli. This focus on their internal state could produce attentional defects (Guillem et al., 2011) and trigger behavioral rigidity (Granon et al., 2003; de Chaumont et al., 2012). It was previously shown that elevation of catecholamines in the PFC inhibited prefrontal functional activity during stress (Arnsten, 2009) and that $\beta 2^{-/-}$mice exhibited constitutive PFC noradrenaline elevation (Coura et al., 2013). A schematic of the catecholamine effect on PFC physiology exhibited a classical inverted U-shape (Arnsten, 2009); this relationship may underlie the inflexible social behavior observed in $\beta 2^{-/-}$mice, as well as their even more inflexible behavior after stress.

In conclusion, stress in $\beta 2^{-/-}$mice produced a dramatic reduction in the social repertoire, a clustering of behavioral sequences, emergence of aggressiveness, and apparent social normalization.

\section{STRESS EFFECTS: SIMILARITIES AND DIFFERENCES IN C57BL/6J AND $\boldsymbol{\beta 2}^{-/-}$MICE}

C57BL/6J and $\beta 2^{-/-}$mice exhibited similarly low baseline levels of corticosterone. Also, their levels of plasma corticosterone were comparable after immobilization stress and after stress followed by novelty exploration. This reinforced the idea that the behavioral differences reported here between stressed and not stressed C57BL/6J and $\beta 2^{-/-}$mice could not be accounted for by plasma corticosterone absolute levels. However, variation in these levels differed in both genotypes: it remained stable whether animals explored novelty or were only stressed in C57BL/6J mice, whereas it significantly dropped after novelty exploration despite previous stress in $\beta 2^{-/-}$mice. $\beta 2^{-/-}$mice seemed to be more reactive to restraint stress than $\mathrm{C} 57 \mathrm{BL} / 6 \mathrm{~J}$ mice. As mentioned above, this provided evidence that $\beta 2^{-/-}$mice were more sensitive to their internal status than to external cues, leading, in consequences, to a larger variation in their corticosterone levels in between different behavioral conditions. The comparison between stressed C57BL/6J and stressed $\beta 2^{-/-}$mice showed that acute stress tended to stereotype social actions of both mouse genotypes, and thus, it made both of them less flexible. This finding goes along with recent data obtained in humans, which showed that cold stress imposed before an instrumental task promoted habits (Schwabe and Wolf, 2009). As discussed above, this 
stress response also reminded behavior observed after NA PFC depletion, suggesting that acute stress may cause an imbalance in the NA levels in the PFC or, more generally, it may reflect impairment in PFC functions (Arnsten, 2009; Del Arco and Mora, 2009). This interpretation would be consistent with our previous findings that flexible social behaviors required functional nAChRs within the PFC (Avale et al., 2011), as they control the release of multiple ascending neurotransmitters in this brain region (dos Santos Coura and Granon, 2012).

\section{CONCLUSIONS}

The present exhaustive behavioral analysis revealed that acute stress in adulthood was sufficient to trigger a marked increase in aggressiveness in both $\mathrm{C} 57 \mathrm{BL} / 6 \mathrm{~J}$ and $\beta 2^{-/-}$mouse genotypes. Because $\beta 2^{-/-}$mice lacked nicotinic receptors, these results showed that aggressive bursts were not linked to nAChR function. We further showed that they were not linked to plasma corticosterone levels. In contrast, stress dramatically increased dominance only in C57BL/6J mice; this finding supports the notion that dominance and aggressiveness are unrelated processes, with only dominance depending on functional nAChRs. Acute stress impoverished mouse social interactions by altering the relationship between behavioral classes, and the classes altered depended on whether the mice exhibited a flexible or pathological social pattern. Thus, stress induced behavioral rigidity in "socially competent" animals, and it worsened rigid behavior in pathological models.

Taken together, these data showed that a unique experimental framework could tease apart behaviors in mice that represent components of the vicious stress-aggression cycle proposed in humans (Craig, 2007).

\section{AUTHOR CONTRIBUTIONS}

Substantial contributions to the conception of the work: Sylvie Granon, Jean-Christophe Olivo-Marin, to the design of the work: Anne Nosjean, Sylvie Granon, to the acquisition analysis: Anne Nosjean, Arnaud Cressant, Fabrice de Chaumont, Frédéric Chauveau, to the interpretation of data: Anne Nosjean, Sylvie Granon, Arnaud Cressant, Fabrice de Chaumont, Frédéric Chauveau. Drafting the work: Anne Nosjean, Sylvie Granon; critical revision of the work: Anne Nosjean, Sylvie Granon, Arnaud Cressant, Fabrice de Chaumont, Frédéric Chauveau, Jean-Christophe Olivo-Marin. Final approval of the version to be published and agreement for all aspects of the work: Anne Nosjean, Sylvie Granon, Arnaud Cressant, Fabrice de Chaumont, Frédéric Chauveau, Jean-Christophe Olivo-Marin.

\section{ACKNOWLEDGMENTS}

This work was supported by the Centre National de la Recherche Scientifique (CNRS, UMR 8195), by the Université Paris Sud 11 (Chaire d'Excellence to Sylvie Granon). It was also supported in part by a grant from the Agence Nationale de la Recherche.

\section{SUPPLEMENTARY MATERIAL}

The Supplementary Material for this article can be found online at: http://www.frontiersin.org/journal/10.3389/fnbeh. 2014.00447/abstract

\section{REFERENCES}

Adolphs, R., and Anderson, D. (2013). Social and emotional neuroscience. Curr. Opin. Neurobiol. 23, 291-293. doi: 10.1016/j.conb.2013.04.011

Adolphs, R. (2010). Conceptual challenges and directions for social neuroscience. Neuron 65, 752-767. doi: 10.1016/j.neuron.2010.03.006

Anderson, S. M., and Brunzell, D. H. (2012). Low dose nicotine and antagonism of beta2 subunit containing nicotinic acetylcholine receptors have similar effects on affective behavior in mice. PLoS ONE 7:e48665. doi: 10.1371/journal.pone.0048665

Anisman, H., and Matheson, K. (2005). Stress, depression, and anhedonia: caveats concerning animal models. Neurosci. Biobehav. Rev. 29, 525-546. doi: 10.1016/j.neubiorev.2005.03.007

Arakawa, H., Arakawa, K., Blanchard, D. C., and Blanchard, R. J. (2008a). A new test paradigm for social recognition evidenced by urinary scent marking behavior in C57BL/6J mice. Behav. Brain Res. 190, 97-104. doi: 10.1016/j.bbr.2008. 02.009

Arakawa, H., Blanchard, D. C., Arakawa, K., Dunlap, C., and Blanchard, R. J. (2008b). Scent marking behavior as an odorant communication in mice. Neurosci. Biobehav. Rev. 32, 1236-1248. doi: 10.1016/j.neubiorev.2008.05.012

Arakawa, H., Blanchard, D. C., and Blanchard, R. J. (2007). Colony formation of C57BL/6J mice in visible burrow system: identification of eusocial behaviors in a background strain for genetic animal models of autism. Behav. Brain Res. 176, 27-39. doi: 10.1016/j.bbr.2006.07.027

Arnsten, A. F. (2009). Stress signalling pathways that impair prefrontal cortex structure and function. Nat. Rev. Neurosci. 10, 410-422. doi: 10.1038/ $\operatorname{nrn} 2648$

Arregi, A., Azpiroz, A., Fano, E., and Garmendia, L. (2006). Aggressive behavior: Implications of dominance and subordination for the study of mental disorders. Aggress. Violent Behav. 11, 394-414. doi: 10.1016/j.avb.2006.01.005

Avale, M. E., Chabout, J., Pons, S., Serreau, P., De Chaumont, F., Olivo-Marin, J. C., et al. (2011). Prefrontal nicotinic receptors control novel social interaction between mice. FASEB J. 25, 2145-2155. doi: 10.1096/fj.10-178558

Avale, M. E., Faure, P., Pons, S., Robledo, P., Deltheil, T., David, D. J., et al. (2008). Interplay of beta $2^{*}$ nicotinic receptors and dopamine pathways in the control of spontaneous locomotion. Proc. Natl. Acad. Sci. U.S.A. 105, 15991-15996. doi: 10.1073/pnas.0807635105

Barik, J., Marti, F., Morel, C., Fernandez, S. P., Lanteri, C., Godeheu, G., et al. (2013). Chronic stress triggers social aversion via glucocorticoid receptor in dopaminoceptive neurons. Science 339, 332-335. doi: 10.1126/science. 1226767

Beerling, W., Koolhaas, J. M., Ahnaou, A., Bouwknecht, J. A., de Boer, S. F., Meerlo, P., et al. (2011). Physiological and hormonal responses to novelty exposure in rats are mainly related to ongoing behavioral activity. Physiol. Behav. 103, 412-420. doi: 10.1016/j.physbeh.2011.03.014

Besson, M., Suarez, S., Cormier, A., Changeux, J. P., and Granon, S. (2008). Chronic nicotine exposure has dissociable behavioural effects on control and beta2-/- mice. Behav. Genet. 38, 503-514. doi: 10.1007/s10519-0089216-1

Blanchard, D. C., Fukunaga-Stinson, C., Takahashi, L. K., Flannelly, K. J. A., and Blanchard, R. J. (1984). Dominance and agression in social groups of male and female rats. Behav. Process. 31-48. doi: 10.1016/0376-6357(84)90006-8

Blanchard, R. J., Wall, P. M., and Blanchard, D. C. (2003). Problems in the study of rodent aggression. Horm. Behav. 44, 161-170. doi: 10.1016/S0018506X(03)00127-2

Buckner, J. D., Heimberg, R. G., Ecker, A. H., and Vinci, C. (2013). A biopsychosocial model of social anxiety and substance use. Depress. Anxiety 30, 276-284. doi: 10.1002/da.22032

Butts, K. A., Floresco, S. B., and Phillips, A. G. (2013). Acute stress impairs set-shifting but not reversal learning. Behav. Brain Res. 252, 222-229. doi: 10.1016/j.bbr.2013.06.007

Cambon, K., Dos-Santos Coura, R., Groc, L., Carbon, A., Weissmann, D., Changeux, J. P., et al. (2010). Aggressive behavior during social interaction in mice is controlled by the modulation of tyrosine hydroxylase expression in the prefrontal cortex. Neuroscience 171, 840-851. doi: 10.1016/j.neuroscience.2010.09.015

Chabout, J., Cressant, A., Hu, X., Edeline, J. M., and Granon, S. (2013). Making choice between competing rewards in uncertain vs. safe social environment: role of neuronal nicotinic receptors of acetylcholine. Front. Hum. Neurosci. 7:468. doi: 10.3389/fnhum.2013.00468 
Chaouloff, F., and Groc, L. (2011). Temporal modulation of hippocampal excitatory transmission by corticosteroids and stress. Front. Neuroendocrinol. 32, 25-42. doi: 10.1016/j.yfrne.2010.07.004

Chauveau, F., Tronche, C., Pierard, C., Liscia, P., Drouet, I., Coutan, M., et al. (2010). Rapid stress-induced corticosterone rise in the hippocampus reverses serial memory retrieval pattern. Hippocampus 20, 196-207. doi: 10.1002/hipo.20605

Chichinadze, K., Chichinadze, N., and Lazarashvili, A. (2011). Hormonal and neurochemical mechanisms of aggression and a new classification of aggressive behavior. Aggress. Violent Behav. 16, 461-472. doi: 10.1016/j.avb.2011.03.002

Clark, B. J., Hamilton, D. A., and Whishaw, I. Q. (2006). Motor activity (exploration) and formation of home bases in mice (C57BL/6) influenced by visual and tactile cues: modification of movement distribution, distance, location, and speed. Physiol. Behav. 87, 805-816. doi: 10.1016/j.physbeh.2006.01.026

Cohen, J. D., and Aston-Jones, G. (2005). Cognitive neuroscience: decision amid uncertainty. Nature 436, 471-472. doi: 10.1038/436471a

Cohen, J. D., Mcclure, S. M., and Yu, A. J. (2007). Should I stay or should I go? How the human brain manages the trade-off between exploitation and exploration. Philos. Trans. R. Soc. Lond. B Biol. Sci. 362, 933-942. doi: 10.1098/rstb.2007.2098

Coura, R. S., Cressant, A., Xia, J., De Chaumont, F., Olivo-Marin, J. C., Pelloux, Y., et al. (2013). Nonaggressive and adapted social cognition is controlled by the interplay between noradrenergic and nicotinic receptor mechanisms in the prefrontal cortex. FASEB J. 27, 4343-4354. doi: 10.1096/fj.13-231084

Craig, I. W. (2007). The importance of stress and genetic variation in human aggression. Bioessays 29, 227-236. doi: 10.1002/bies.20538

Crawley, J. N. (2000). What is Wrong With My Mouse? / Behavioral Phenotyping of Transgenic and Knockout Mice. New York, NY: John Wiley and Sons

Das, A., Kapoor, K., Sayeepriyadarshini, A. T., Dikshit, M., Palit, G., and Nath, C. (2000). Immobilization stress-induced changes in brain acetylcholinesterase activity and cognitive function in mice. Pharmacol. Res. 42, 213-217. doi: 10.1006/phrs.2000.0678

De Boer, S. F., and Van der Gugten, J. (1987). Daily variations in plasma noradrenaline, adrenaline and corticosterone concentrations in rats. Physiol. Behav. 40, 323-328. doi: 10.1016/0031-9384(87)90054-0

de Chaumont, F., Coura, R. D., Serreau, P., Cressant, A., Chabout, J., Granon, S., et al. (2012). Computerized video analysis of social interactions in mice. Nat. Methods 9, 410-417. doi: 10.1038/nmeth.1924

Del Arco, A., and Mora, F. (2009). Neurotransmitters and prefrontal cortexlimbic system interactions: implications for plasticity and psychiatric disorders. J. Neural Transm. 116, 941-952. doi: 10.1007/s00702-009-0243-8

Del Giudice, M., Ellis, B. J., and Shirtcliff, E. A. (2011). The adaptive calibration model of stress responsivity. Neurosci. Biobehav. Rev. 35, 1562-1592. doi: 10.1016/j.neubiorev.2010.11.007

Deschenes, M., Moore, J., and Kleinfeld, D. (2012). Sniffing and whisking in rodents. Curr. Opin. Neurobiol. 22, 243-250. doi: 10.1016/j.conb.2011.11.013

dos Santos Coura, R., and Granon, S. (2012). Prefrontal neuromodulation by nicotinic receptors for cognitive processes. Psychopharmacology 221, 1-18. doi: 10.1007/s00213-011-2596-6

Fairless, A. H., Katz, J. M., Vijayvargiya, N., Dow, H. C., Kreibich, A. S., Berrettini, W. H., et al. (2013). Development of home cage social behaviors in BALB/cJ vs. C57BL/6J mice. Behav. Brain Res. 237, 338-347. doi: 10.1016/j.bbr.2012.08.051

Gasbarri, A., and Tomaz, C. (2012). Memory and motivational/emotional processes. Front. Behav. Neurosci. 6:71. doi: 10.3389/fnbeh.2012.00071

Ginsberg, S. D., Che, S., Hashim, A., Zavadil, J., Cancro, R., Lee, S. H., et al. (2011). Differential regulation of catechol-O-methyltransferase expression in a mouse model of aggression. Brain Struct. Funct. 216, 347-356. doi: 10.1007/s00429011-0315-Z

Granon, S., Faure, P., and Changeux, J. P. (2003). Executive and social behaviors under nicotinic receptor regulation. Proc. Natl. Acad. Sci. U.S.A. 100, 9596-9601. doi: 10.1073/pnas.1533498100

Grzadzinski, R., Huerta, M., and Lord, C. (2013). DSM-5 and autism spectrum disorders (ASDs): an opportunity for identifying ASD subtypes. Mol. Autism 4:12. doi: 10.1186/2040-2392-4-12

Guillem, K., Bloem, B., Poorthuis, R. B., Loos, M., Smit, A. B., Maskos, U., et al. (2011). Nicotinic acetylcholine receptor $\beta 2$ subunits in the medial prefrontal cortex control attention. Science 333, 888-891. doi: 10.1126/science.1207079

Haller, J., Mikics, E., Halasz, J., and Toth, M. (2005). Mechanisms differentiating normal from abnormal aggression: glucocorticoids and serotonin. Eur. J. Pharmacol. 526, 89-100. doi: 10.1016/j.ejphar.2005.09.064
Javidi, H., and Yadollahie, M. (2012). Post-traumatic stress disorder. Int. J. Occup. Environ. Med. 3, 2-9.

Kalsbeek, A., van der Vliet, J., and Buijs, R. M. (1996). Decrease of endogenous vasopressin release necessary for expression of the circadian rise in plasma corticosterone: a reverse microdialysis study. J. Neuroendocrinol. 8, 299-307. doi: 10.1046/j.1365-2826.1996.04597.x

Kehagia, A. A., Murray, G. K., and Robbins, T. W. (2010). Learning and cognitive flexibility: frontostriatal function and monoaminergic modulation. Curr. Opin. Neurobiol. 20, 199-204. doi: 10.1016/j.conb.2010.01.007

Kobayashi, Y., Sano, Y., Vannoni, E., Goto, H., Suzuki, H., Oba, A., et al. (2013). Genetic dissection of medial habenula-interpeduncular nucleus pathway function in mice. Front. Behav. Neurosci. 7:17. doi: 10.3389/fnbeh.2013.00017

Koolhaas, J. M., Korte, S. M., De Boer, S. F., Van Der Vegt, B. J., Van Reenen, C. G., Hopster, H., et al. (1999). Coping styles in animals: current status in behavior and stress-physiology. Neurosci. Biobehav. Rev. 23, 925-935. doi: 10.1016/S01497634(99)00026-3

Krach, S., Paulus, F. M., Bodden, M., and Kircher, T. (2010). The rewarding nature of social interactions. Front. Behav. Neurosci. 4:22. doi: 10.3389/fnbeh.2010.00022

Lasko, N. B., Gurvits, T. V., Kuhne, A. A., Orr, S. P., and Pitman, R. K. (1994). Aggression and its correlates in Vietnam veterans with and without chronic posttraumatic stress disorder. Compr. Psychiatry 35, 373-381. doi: 10.1016/0010-440X(94)90278-X

Le Roy, I., Pothion, S., Mortaud, S., Chabert, C., Nicolas, L., Cherfouh, A., et al. (2000). Loss of aggression, after transfer onto a C57BL/6J background, in mice carrying a targeted disruption of the neuronal nitric oxide synthase gene. Behav. Genet. 30, 367-373. doi: 10.1023/A:1002796404278

Lukkes, J. L., Watt, M. J., Lowry, C. A., and Forster, G. L. (2009). Consequences of post-weaning social isolation on anxiety behavior and related neural circuits in rodents. Front. Behav. Neurosci. 3:18. doi: 10.3389/neuro.08.018.2009

Lupien, S. J., Mcewen, B. S., Gunnar, M. R., and Heim, C. (2009). Effects of stress throughout the lifespan on the brain, behaviour and cognition. Nat. Rev. Neurosci. 10, 434-445. doi: 10.1038/nrn2639

Marquez, C., Poirier, G. L., Cordero, M. I., Larsen, M. H., Groner, A., Marquis, J., et al. (2013). Peripuberty stress leads to abnormal aggression, altered amygdala and orbitofrontal reactivity and increased prefrontal MAOA gene expression. Trans. Psychiatry 3:e216. doi: 10.1038/tp.2012.144

Marwick, K., and Hall, J. (2008). Social cognition in schizophrenia: a review of face processing. Br. Med. Bull. 88, 43-58. doi: 10.1093/bmb/ldn035

Maubourguet, N., Lesne, A., Changeux, J. P., Maskos, U., and Faure, P. (2008) Behavioral sequence analysis reveals a novel role for beta $2 *$ nicotinic receptors in exploration. PLoS Comput. Biol. 4:e1000229. doi: 10.1371/journal.pcbi.1000229

Maxson, S. C. (2009). "The genetics of offensive aggression in mice," in Handbook of Behavior Genetics, ed K. Yong-Kyu (New York, NY: Springer), 301-316. doi: 10.1007/978-0-387-76727-7_21

McEwen, B. S. (2006). Protective and damaging effects of stress mediators: central role of the brain. Dialogues Clin. Neurosci. 8, 367-381.

McEwen, B. S. (2007). Physiology and neurobiology of stress and adaptation: central role of the brain. Physiol. Rev. 87, 873-904. doi: 10.1152/physrev.00041.2006

McEwen, B. S. (2012). Brain on stress: how the social environment gets under the skin. Proc. Natl. Acad. Sci. U.S.A. 109(Suppl. 2), 17180-17185. doi: 10.1073/pnas.1121254109

Miczek, K. A., Maxson, S. C., Fish, E. W., and Faccidomo, S. (2001). Aggressive behavioral phenotypes in mice. Behav. Brain Res. 125, 167-181. doi 10.1016/S0166-4328(01)00298-4

Miczek, K. A., and O’Donnell, J. M. (1978). Intruder-evoked aggression in isolated and nonisolated mice: effects of psychomotor stimulants and L-dopa. Psychopharmacology (Berl) 57, 47-55. doi: 10.1007/BF00426957

Mineur, Y. S., Obayemi, A., Wigestrand, M. B., Fote, G. M., Calarco, C. A., Li, A. M., et al. (2013). Cholinergic signaling in the hippocampus regulates social stress resilience and anxiety- and depression-like behavior. Proc. Natl. Acad. Sci. U.S.A. 110, 3573-3578. doi: 10.1073/pnas.1219731110

Morrison, A. S., and Heimberg, R. G. (2013). Social anxiety and social anxiety disorder. Annu. Rev. Clin. Psychol. 9, 249-274. doi: 10.1146/annurev-clinpsy050212-185631

Moy, S. S., Nadler, J. J., Young, N. B., Nonneman, R. J., Segall, S. K., Andrade, G. M., et al. (2008). Social approach and repetitive behavior in eleven inbred mouse strains. Behav. Brain Res. 191, 118-129. doi: 10.1016/j.bbr.2008. 03.015 
Neumann, I. D., Veenema, A. H., and Beiderbeck, D. I. (2010). Aggression and anxiety: social context and neurobiological links. Front. Behav. Neurosci. 4:12. doi: $10.3389 /$ fnbeh.2010.00012

Nevo, E. (2007). "Evolution of Pacifism and sociality in blind mole rats", in Rodent Societies. An Ecological and Evolutionary Perspective, eds Jerry W and Paul Sherman (Chicago, IL: University of Chicago Press), 291-302.

Nyberg, J., Sandnabba, K., Schalkwyk, L., and Sluyter, F. (2004). Genetic and environmental (inter)actions in male mouse lines selected for aggressive and nonaggressive behavior. Genes Brain Behav. 3, 101-109. doi: 10.1111/j.1601183X.2003.0056.x

Owings, D. H., and Coss, R. G. (2007). "Social and antipredator systems: intertwining links in multiple time frames," in Rodent Societies. An Ecological and Evolutionary Perspective, eds Jerry Wolff and Paul Sherman (Chicago, IL: University of Chicago Press), 305-316.

Pabst, S., Brand, M., and Wolf, O. T. (2013a). Stress and decision making: a few minutes make all the difference. Behav. Brain Res. 250, 39-45. doi: 10.1016/j.bbr.2013.04.046

Pabst, S., Schoofs, D., Pawlikowski, M., Brand, M., and Wolf, O. T. (2013b). Paradoxical effects of stress and an executive task on decisions under risk. Behav. Neurosci. 127, 369-379. doi: 10.1037/a0032334

Panksepp, J. B., and Lahvis, G. P. (2011). Rodent empathy and affective neuroscience. Neurosci. Biobehav. Rev. 35, 1864-1875. doi: 10.1016/j.neubiorev.2011.05.013

Pavic, L., Gregurek, R., Petrovic, R., Petrovic, D., Varda, R., Vukusic, H., et al. (2003). Alterations in brain activation in posttraumatic stress disorder patients with severe hyperarousal symptoms and impulsive aggressiveness. Eur. Arch. Psychiatry Clin. Neurosci. 253, 80-83. doi: 10.1007/s00406-003-0411-z

Picciotto, M. R., Higley, M. J., and Mineur, Y. S. (2012). Acetylcholine as a neuromodulator: cholinergic signaling shapes nervous system function and behavior. Neuron 76, 116-129. doi: 10.1016/j.neuron.2012.08.036

Picciotto, M. R., Zoli, M., Lena, C., Bessis, A., Lallemand, Y., Le Novere, N., et al. (1995). Abnormal avoidance learning in mice lacking functional high-affinity nicotine receptor in the brain. Nature 374, 65-67. doi: 10.1038/374065a0

Porcelli, A. J., and Delgado, M. R. (2009). Acute stress modulates risk taking in financial decision making. Psychol. Sci. 20, 278-283. doi: 10.1111/j.14679280.2009.02288.x

Puglisi-Allegra, S., and Cabib, S. (1985). The effect of age on two kinds of aggressive behavior in inbred strains of mice. Dev. Psychobiol. 18, 477-482. doi 10.1002/dev.420180605

Quartermain, D., Stone, E. A., and Charbonneau, G. (1996). Acute stress disrupts risk assessment behavior in mice. Physiol. Behav. 59, 937-940. doi: 10.1016/0031-9384(95)02140-X

Ritsner, M. S., Mar, M., Arbitman, M., and Grinshpoon, A. (2013). Symptom severity scale of the DSM5 for schizophrenia, and other psychotic disorders: diagnostic validity and clinical feasibility. Psychiatry Res. 208, 1-8. doi: 10.1016/j.psychres.2013.02.029

Roozendaal, B., Mcewen, B. S., and Chattarji, S. (2009). Stress, memory and the amygdala. Nat. Rev. Neurosci. 10, 423-433. doi: 10.1038/nrn2651

Roozendaal, B. (2002). Stress and memory: opposing effects of glucocorticoids on memory consolidation and memory retrieval. Neurobiol. Learn. Mem. 78, 578-595. doi: 10.1006/nlme.2002.4080

Roozendaal, B. (2003). Systems mediating acute glucocorticoid effects on memory consolidation and retrieval. Prog. Neuropsychopharmacol. Biol. Psychiatry 27, 1213-1223. doi: 10.1016/j.pnpbp.2003.09.015

Roubertoux, P. L., Le Roy, I., Mortaud, S., Perez-Diaz, F., and Tordjman, S. (1999). Measuring Aggression in the Mouse. Amsterdam: Elsevier.

Sakakibara, H., Suzuki, A., Kobayashi, A., Motoyama, K., Matsui, A., Sayama, K., et al. (2012). Social isolation stress induces hepatic hypertrophy in C57BL/6J mice. J. Toxicol. Sci. 37, 1071-1076. doi: 10.2131/jts.37.1071

Sandi, C., Cordero, M. I., Ugolini, A., Varea, E., Caberlotto, L., and Large, C. H. (2008). Chronic stress-induced alterations in amygdala responsiveness and behavior-modulation by trait anxiety and corticotropin-releasing factor systems. Eur. J. Neurosci. 28, 1836-1848. doi: 10.1111/j.1460-9568.2008 06451.x

Sandi, C., and Pinelo-Nava, M. T. (2007). Stress and memory: behavioral effects and neurobiological mechanisms. Neural Plast 2007:78970. doi: $10.1155 / 2007 / 78970$

Sankoorikal, G. M., Kaercher, K. A., Boon, C. J., Lee, J. K., and Brodkin, E. S. (2006). A mouse model system for genetic analysis of sociability: C57BL/6 versus BALB/cJ inbred mouse strains. Biol. Psychiatry 59, 415-423. doi: 10.1016/j.biopsych.2005.07.026

Schultz, A. S., Nowatzki, J., and Ronson, G. (2013). Effects of household socialization on youth susceptibility to smoke: differences between youth age groups and trends over time. Am. J. Public Health 103, e39-e42. doi: 10.2105/AJPH.2013.301344

Schwabe, L., and Wolf, O. T. (2009). Stress prompts habit behavior in humans. J. Neurosci. 29, 7191-7198. doi: 10.1523/JNEUROSCI.0979-09.2009

Serreau, P., Chabout, J., Suarez, S. V., Naude, J., and Granon, S. (2011). Beta2-containing neuronal nicotinic receptors as major actors in the flexible choice between conflicting motivations. Behav. Brain Res. 225, 151-159. doi: 10.1016/j.bbr.2011.07.016

Shafiei, N., Gray, M., Viau, V., and Floresco, S. B. (2012). Acute stress induces selective alterations in cost/benefit decision-making. Neuropsychopharmacology 37, 2194-2209. doi: 10.1038/npp.2012.69

Silverman, J. L., Yang, M., Lord, C., and Crawley, J. N. (2010). Behavioural phenotyping assays for mouse models of autism. Nat. Rev. Neurosci. 11, 490-502. doi: $10.1038 / \mathrm{nrn} 2851$

Starcke, K., and Brand, M. (2012). Decision making under stress: a selective review. Neurosci Biobehav Rev 36, 1228-1248. doi: 10.1016/j.neubiorev.2012.02.003

Thoeringer, C. K., Sillaber, I., Roedel, A., Erhardt, A., Mueller, M. B., Ohl, F., et al. (2007). The temporal dynamics of intrahippocampal corticosterone in response to stress-related stimuli with different emotional and physical load: an in vivo microdialysis study in $\mathrm{C} 57 \mathrm{BL} / 6$ and $\mathrm{DBA} / 2$ inbred mice. Psychoneuroendocrinology 32, 746-757. doi: 10.1016/j.psyneuen.2007.05.005

Toledo-Rodriguez, M., and Sandi, C. (2011). Stress during adolescence increases novelty seeking and risk-taking behavior in male and female rats. Front. Behav. Neurosci. 5:17. doi: 10.3389/fnbeh.2011.00017

Toth, M., Mikics, E., Tulogdi, A., Aliczki, M., and Haller, J. (2011). Post-weaning social isolation induces abnormal forms of aggression in conjunction with increased glucocorticoid and autonomic stress responses. Horm. Behav. 60, 28-36. doi: 10.1016/j.yhbeh.2011.02.003

Toth, M., Tulogdi, A., Biro, L., Soros, P., Mikics, E., and Haller, J. (2012). The neural background of hyper-emotional aggression induced by post-weaning social isolation. Behav. Brain Res. 233, 120-129. doi: 10.1016/j.bbr.2012.04.025

Tsai, S. J., Yeh, H. L., Hong, C. J., Liou, Y. J., Yang, A. C., Liu, M. E., et al. (2012). Association of CHRNA4 polymorphism with depression and loneliness in elderly males. Genes Brain Behav. 11, 230-234. doi: 10.1111/j.1601183X.2011.00741.x

Tulogdi, A., Toth, M., Barsvari, B., Biro, L., Mikics, E., and Haller, J. (2014) Effects of resocialization on post-weaning social isolation-induced abnormal aggression and social deficits in rats. Dev. Psychobiol. 56, 49-57. doi: 10.1002/dev. 21090

Umukoro, S., Aladeokin, A. C., and Eduviere, A. T. (2013). Aggressive behavior: a comprehensive review of its neurochemical mechanisms and management. Aggress. Violent Behav. 18, 195-203. doi: 10.1016/j.avb.2012.11.002

Van Der Kooij, M. A., and Sandi, C. (2012). Social memories in rodents: methods, mechanisms and modulation by stress. Neurosci. Biobehav. Rev. 36, 1763-1772. doi: 10.1016/j.neubiorev.2011.10.006

Varlinskaya, E. I., Spear, L. P., and Spear, N. E. (1999). Social behavior and social motivation in adolescent rats: role of housing conditions and partner's activity. Physiol. Behav. 67, 475-482. doi: 10.1016/S0031-9384(98)00285-6

Veenema, A. H. (2009). Early life stress, the development of aggression and neuroendocrine and neurobiological correlates: what can we learn from animal models? Front. Neuroendocrinol. 30, 497-518. doi: 10.1016/j.yfrne.2009.03.003

Von Dawans, B., Fischbacher, U., Kirschbaum, C., Fehr, E., and Heinrichs, M. (2012). The social dimension of stress reactivity: acute stress increases prosocial behavior in humans. Psychol. Sci. 23, 651-660. doi: 10.1177/0956797611431576

Weinberg, M. S., Girotti, M., and Spencer, R. L. (2007). Restraint-induced fra2 and c-fos expression in the rat forebrain: relationship to stress duration. Neuroscience 150, 478-486. doi: 10.1016/j.neuroscience.2007.09.013

Wiklund, A., Granon, S., Faure, P., Sundman, E., Changeux, J. P., and Eriksson, L. I. (2009). Object memory in young and aged mice after sevoflurane anaesthesia. Neuroreport 20, 1419-1423. doi: 10.1097/WNR.0b013e328330cd2b

Wolfe, J., Mende, C., and Brecht, M. (2011). Social facial touch in rats. Behav. Neurosci. 125, 900-910. doi: 10.1037/a0026165

Wood, G. E., Young, L. T., Reagan, L. P., and Mcewen, B. S. (2003). Acute and chronic restraint stress alter the incidence of social conflict in male rats. Horm. Behav. 43, 205-213. doi: 10.1016/S0018-506X(02)00026-0 
Yang, M., Abrams, D. N., Zhang, J. Y., Weber, M. D., Katz, A. M., Clarke, A. M., et al. (2012). Low sociability in BTBR $\mathrm{T}+\mathrm{tf} / \mathrm{J}$ mice is independent of partner strain. Physiol. Behav. 107, 649-662. doi: 10.1016/j.physbeh.2011.12.025

Yang, M., Scattoni, M. L., Zhodzishsky, V., Chen, T., Caldwell, H., Young, W. S. III., McFarlane, H. G., et al. (2007). Social approach behaviors are similar on conventional versus reverse lighting cycles, and in replications across cohorts, in BTBR $\mathrm{T}+\mathrm{tf} / \mathrm{J}, \mathrm{C} 57 \mathrm{BL} / 6 \mathrm{~J}$, and Vasopressin Receptor $1 \mathrm{~B}$ mutant mice. Front. Behav. Neurosci. 1, 1-9. doi: 10.3389/neuro.08.001.2007

Yang, M., Weber, M. D., and Crawley, J. N. (2008). Light phase testing of social behaviors: not a problem. Front. Neurosci. 2, 186-191. doi: 10.3389/neuro.01.029.2008

Yohe, L. R., Suzuki, H., and Lucas, L. R. (2012). Aggression is suppressed by acute stress but induced by chronic stress: immobilization effects on aggression, hormones, and cortical 5-HT(1B)/ striatal dopamine $\mathrm{D}(2)$ receptor density. Cogn. Affect. Behav. Neurosci. 12, 446-459. doi: 10.3758/s13415-012-0095-9

Yu, A. J., and Dayan, P. (2005). Uncertainty, neuromodulation, and attention. Neuron 46, 681-692. doi: 10.1016/j.neuron.2005.04.026

Zafeiriou, D. I., Ververi, A., Dafoulis, V., Kalyva, E., and Vargiami, E. (2013). Autism spectrum disorders: the quest for genetic syndromes. Am. J. Med. Genet. B Neuropsychiatr. Genet. 162B, 327-366. doi: 10.1002/ajmg.b.32152

Zoladz, P. R., and Diamond, D. M. (2013). Current status on behavioral and biological markers of PTSD: a search for clarity in a conflicting literature. Neurosci. Biobehav. Rev. 37, 860-895. doi: 10.1016/j.neubiorev.2013.03.024
Zoli, M., Picciotto, M. R., Ferrari, R., Cocchi, D., and Changeux, J. P. (1999). Increased neurodegeneration during ageing in mice lacking high-affinity nicotine receptors. EMBO J. 18, 1235-1244. doi: 10.1093/emboj/18. 5.1235

Conflict of Interest Statement: The authors declare that the research was conducted in the absence of any commercial or financial relationships that could be construed as a potential conflict of interest.

Received: 18 March 2014; accepted: 10 December 2014; published online: 06 January 2015.

Citation: Nosjean A, Cressant A, de Chaumont F, Olivo-Marin J-C, Chauveau F and Granon S (2015) Acute stress in adulthood impoverishes social choices and triggers aggressiveness in preclinical models. Front. Behav. Neurosci. 8:447. doi: 10.3389/fnbeh. 2014.00447

This article was submitted to the journal Frontiers in Behavioral Neuroscience. Copyright (C) 2015 Nosjean, Cressant, de Chaumont, Olivo-Marin, Chauveau and Granon. This is an open-access article distributed under the terms of the Creative Commons Attribution License (CC BY). The use, distribution or reproduction in other forums is permitted, provided the original author(s) or licensor are credited and that the original publication in this journal is cited, in accordance with accepted academic practice. No use, distribution or reproduction is permitted which does not comply with these terms. 